\title{
Equilibrium Moment Restrictions on Asset Returns: Normal and Crisis Periods
}

\author{
P Simmons \\ Department of Economics \\ University of York \\ York YO10 5DD \\ UK
}

email: peter.simmons@york.ac.uk tel: +441904 433763
$\&$

N Tantisantiwong

School of Business

University of Dundee

Dundee DD1 4HN

UK

email:n.tantisantiwong@dundee.ac.uk tel:+44 1382385838

\begin{abstract}
Empirically the covariance between stock returns varies with their volatility. We seek a robust theoretical explanation of this. With minimal assumptions, we model stochastic properties of equilibrium returns which result from interaction between intertemporal traders and noisy, price sensitive short term traders. The intertemporal traders can have arbitrary investment rules, preferences and information. In all cases we find a set of restrictions between second moments of equilibrium returns. With two assets there is also a bound on the correlation between asset returns. Estimation with second moments of global stock returns supports our theoretical framework. Higher volatility in at least one market can increase comovement among markets. With globalization, covariances between two stock markets can also affect covariances between two other stock markets. We also find that changes in trader behavior between normal and crisis periods leads to changes in the moment restrictions between asset returns.
\end{abstract}

JEL classification: D52; D82; G12

Keywords: short term traders, asset returns, equilibrium moment restrictions, correlation bound 


\title{
Equilibrium Moment Restrictions on Asset Returns: Normal and Crisis Periods
}

\begin{abstract}
Empirically the covariance between stock returns varies with their volatility. We seek a robust theoretical explanation of this. With minimal assumptions, we model stochastic properties of equilibrium returns which result from interaction between intertemporal traders and noisy, price sensitive short term traders. The intertemporal traders can have arbitrary investment rules, preferences and information. In all cases we find a set of restrictions between second moments of equilibrium returns. With two assets there is also a bound on the correlation between asset returns. Estimation with second moments of global stock returns supports our theoretical framework. Higher volatility in at least one market can increase comovement among markets. With globalization, covariances between two stock markets can also affect covariances between two other stock markets. We also find that changes in trader behavior between normal and crisis periods leads to changes in the moment restrictions between asset returns.
\end{abstract}

JEL classification: D52; D82; G12

Keywords: short term traders, asset returns, equilibrium moment restrictions, correlation bound

\section{Introduction}

A key question in finance is what determines the random properties of asset returns. Many of the advances in understanding have come from noticing empirical anomalies that cannot be explained by existing theories. So there have been developments in rational and behavioral financial models such as habit effects (Campbell and Cochrane, 1999), individual heterogeneity (Brav et al., 2002; Chiarella et al., 2011) and incompleteness of markets (Heaton and Lucas, 1996). Using these to explain anomalies requires extraneous additional assumptions on functional form which may however be mis-specified e.g. non-separability over time or skewness of the stochastic discount factor and time varying properties of the risk premium (Brennan et al., 2004). Indeed, the aim is to identify key model components which have predictive and explanatory power, generate precise predictions but at the same time are as general as possible. These are of necessity hard to find.

The empirical facts we focus on are the relations between volatilities and correlations of stock returns and how these relations evolve over time. In recent years, empirical connections between the covariances and volatilities of many asset prices are found. As can 
be seen during the 1997 Asian financial crisis, the 2008 oil crisis and the 2008 global financial crisis, instability in one market spread to others (Diebold and Yilmaz, 2009; Beirne et al., 2009). Liu and Pan (1997) explain their empirical findings on volatility spillover effects from the U.S. and Japan to four other Asian stock markets after the 1987 stock market crash by cross-country equity investing and market contagion. You and Daigler (2010) also find correlations between financial markets and amongst futures contracts. These studies consider pairs of markets but empirically there are multimarket interactions of volatility. Volatility in one market can impact on the correlation between two other markets.

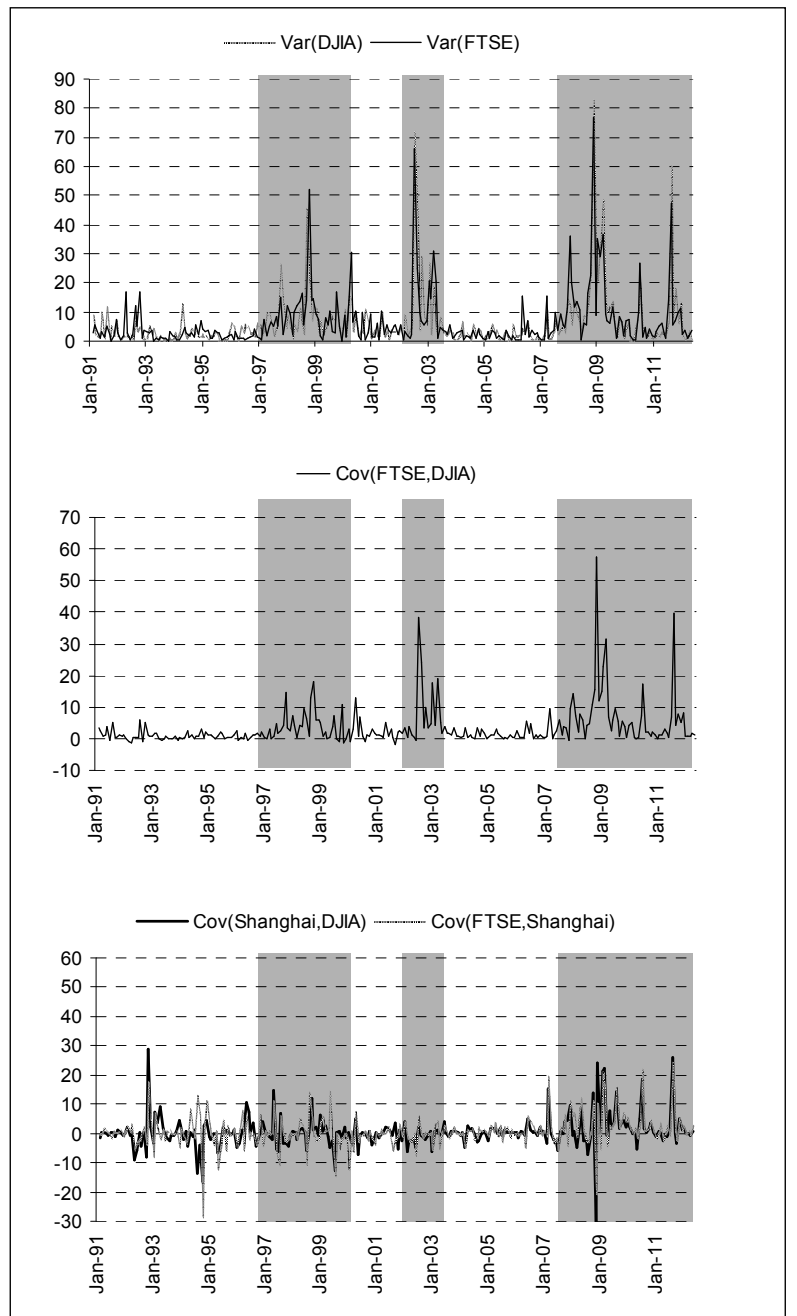

Figure 1: Monthly Variances and Covariances Composite Index Returns

As can be seen from Figure 1, the US Dowjones Industrial Average (DJIA) index return and the UK FTSE100 index return are very volatile during the Asian financial crisis (1997-1999), July 2002- March 2003 (an intensive period of wars due to the 9/11 event), and 
the global financial crisis from 2008. In the same periods, not only are the covariances between these two index returns high, but the covariances between these two index returns and the Shanghai Stock Exchange (SSE) index ${ }^{1}$ are also high especially during both financial crises. Conversely, the covariances are lower in periods of low volatility of the DJIA index return and/or the FTSE100 index return.

There are various factors at work. Kolanovic (2011) argues that some of the recent increase in correlation of returns is due to increasing integration between asset markets and also to the impact of trading rules and risk management strategies. Indeed Kalotychou et al. (2009) and Cappiello et al. (2006) use dynamic conditional correlation (DCC) models, a multivariate GARCH model, to capture the dynamics of asset correlations and their links to volatility. Kalotychou et al. (2009) show that trading strategies which recognize the correlation-volatility link are empirically more profitable than others. This approach relies on an underlying statistical model of the asset returns which does not derive from an explicit economic or market structure. Factor models which distinguish systemic and idiosyncratic risk are similar in that the basic random asset process is the exogenous starting point, which then leads directly to the correlation and volatility structure of returns. Empirical identification of factors can then be based purely on statistical methods like principal components (giving potential difficulties in interpretation of factors) or by empirical correlation of asset returns with systemic effects like macroeconomic variables (e.g. inflation and exchange rates) and with idiosyncratic asset specific factors like the book value of assets of a firm. Bekaert et al. (2005) identify the factors with the relevant market portfolios of global markets in a setting with partial world financial integration. An approach with a much

\footnotetext{
${ }^{1}$ The SSE index is a market capitalisation-weighted stock index of Shanghai Stock Exchange of China with the base date on December 19, 1990. The index was launched on July 15, 1991. Stocks in this market are divided into two classifications: A shares and B shares. Trading in A shares was initially restricted to domestic investor only while B shares are available to both domestic and foreign investors. After reforms in 2002, foreign investors can trade A shares under Qualified Foreign Institutional Investor (QFI) program. A shares are quoted in RMB while B shares are quoted in USD. It's currently composed of 894 constituents.
} 
more market based structure is in Diebold and Strasser (2008) who analyze the effects of micromarket structure noise on pricing and asset returns. In particular strategic behavior of economic agents determines the cross-correlation structure between a latent asset price (its "true value") and the noise in several different micromarket structure frameworks in a variety of leading environments, including those of Roll (1984), Glosten and Milgrom (1985), Kyle (1985), Easley and O'Hara (1992), and Hasbrouck (2002). In these papers, the latent price process is set by an exogenous statistical model. As another approach, Diasakos (2010) finds that wealth effects on the price of risks via the marginal utility of consumption can increase the correlation.

Another empirical aspect is that the correlation pattern between asset returns typically undergoes some structural break in crisis or contagion periods in the market. There is no clear definition of a crisis or contagion period, but generally it involves periods in which asset returns show increases in correlation and volatility, and a departure of the links between these and fundamentals. Bekaert et al. (2005) use asymmetric GARCH modeling of volatility in assets combined with a two-factor CAPM type approach to explore how asset return correlations shift with periods of contagion in an approach which allows for different degrees of market integration. They find that the Mexican crisis generally did not lead to a significant increase in asset correlations but the Asian crisis did and also that contagion effects are more important between European than other markets.

Our main contribution is to develop a framework explaining contemporaneous relationships between variance and covariance of asset returns in an equilibrium financial market setting. In particular our framework explains how the comovement of two asset returns can affect the comovement of other asset returns in the same period. We also explain how this link is affected by short-term trading. Hence we can derive the restrictions on the second moments of asset returns from equilibrium in a multi market model.

Our framework has minimal assumptions on markets and investor motivations yet still 
generates the relations between second moments from a micro-based market model. We find restrictions in the covariance matrix of asset returns whatever the investor motivations are. The only things that are necessary are that there exist some investors who alter their portfolio demands in line with the current pattern of asset prices and expected asset returns as well as some random noise traders. We also find that the absolute value of the correlation between the asset returns has a lower bound which depends on trading of short-term traders. Empirically we find that our framework can explain the contemporaneous relationship between elements of the variance-covariance matrix with higher explanatory power than the alternative in which the covariance of asset returns is only explained by the volatilities of asset returns.

The plan of the paper is to give the basic assumptions and derive the equilibrium asset prices and returns in section 2 for a multi-market case. In section 3 , we compute the first and second moments and derive the moment restrictions. In section 4, with two asset markets we find a lower bound of correlation between two asset returns. Section 5 provides empirical evidence on moment restrictions using the stationary time-varying second moments of six stock market returns. Finally, we conclude in section 6. Algebraic derivations are in the appendix.

\section{Traders and Market Equilibrium}

We take $m$ asset markets, the $i^{t h}$ asset has price $P_{i t+1}$ at time $t+1$ and an expected return at $t+1$ of $\left.E r_{i t+1}=\left(E P_{i t+2}\right)-P_{i t+1}\right) / P_{i t+1} \sim \ln \left(E P_{i t+2} / P_{i t+1}\right)$. At each date there are three categories of traders in each market.

Firstly, there are intertemporal traders who generally are holding long positions but who adjust their portfolios/roll over positions. At time $t+1$ these traders generate aggregate net supplies of each asset, $X_{i t+1}$, which depend on previous prices and are nonrandom in 
volume at time $t+1^{2}$ e.g. current positions come from closing out past positions $x_{i t}^{j}$ of trader $j$ for price/return independent reasons. The aggregate of the trades of this trading group is $X_{i t+1}=\sum_{j} x_{i t}^{j} \quad$ for $i=1, \ldots, m$.

Secondly, there are investors who are sensitive to expected asset returns and who have a one period time horizon. Trader $h$ of this price sensitive group has their view of expected asset returns at time $t+1$ (i.e. $E_{h t+1} r_{i} \sim \ln \left(E_{h t+1} P_{i t+2} / P_{i t+1}\right)$ in each market $\left.i\right)$ and so has a demand for the $i^{t h}$ asset at time $t+1$ given by $f_{i}^{h}\left(1+E_{h t+1} r_{1}, \ldots, 1+E_{h t+1} r_{m}\right)$.

Thirdly, in each market $\mathrm{i}$, there are some pure noise traders and new issues at time $t+1$. Their trades in the $i^{\text {th }}$ asset sum to $\varepsilon_{i t+1}$ which has constant mean $\mu_{i}$ and taken across the $m$ markets, the variance-covariance matrix of the trades of this third group is

$$
\Gamma=E\left(\varepsilon_{t}-\mu\right)\left(\varepsilon_{t}-\mu\right)^{\prime}=\left[\begin{array}{cccc}
\gamma_{11} & \gamma_{12} & \cdots & \gamma_{1 m} \\
\gamma_{12} & \ddots & & \vdots \\
\vdots & & \ddots & \vdots \\
\gamma_{1 m} & \cdots & \cdots & \gamma_{m m}
\end{array}\right]
$$

At time $t+1$ asset prices and so returns adjust to clear the market. Thus, $P_{t+1}=\left(P_{1 t+1}, . . P_{m t+1}\right)$ solves a system of $m$ equations:

$$
X_{i t+1}=\Sigma_{h} f_{i}^{h}\left(1+E_{h t+1} r_{1}, \ldots, 1+E_{h t+1} r_{m}\right)+\varepsilon_{i t+1 .} \quad i=1, \ldots, m .
$$

Our main point is that in equilibrium, since $P_{t+1}$ is in part determined by $\varepsilon_{i t+1}$ where $i=$ $1, \ldots, m$, the asset returns at time $t+1$ are random and will inherit cross market noise trading effects. These cross market effects on equilibrium asset prices, coming through the return sensitivity of flow traders' market activity, lead to restrictions between the volatility and covariance structure of asset returns.

To simplify the solution, the price sensitive flow trader's net demand is assumed to be

${ }^{2} X_{i t+1}$ can also be seen as the net supply by momentum traders in Kelsey et al (2010). These momentum traders base their trade at time $t+1$ on the previous price change from $P_{t-1}$ to $P_{t}$. Thus, $X_{i t+1}$ is nonrandom at time $t+1$. 
linear and common across traders $f_{i}^{h}\left(1+E_{h t+1} r_{1}, \ldots, 1+E_{h t+1} r_{m}\right)=\Sigma_{k} c_{i k}\left(1+E_{h t+1} r_{k}\right)$ for $h=1, \ldots, H$. This is a "reduced form" asset demand by traders which is consistent with alternative decision frameworks. The linearity could arise from common quadratic transaction and management costs of traders. Alternatively the flow traders may be mean-variance investors with the motivation of maximizing utility of wealth at time $t+2, \quad w_{t+2}^{h}=\Sigma_{i}\left(1+r_{i t+1}\right) x_{i t+1}^{h}$ where $x_{i t+1}^{h}$ is investment by trader $h$ in the $i^{\text {th }}$ asset at time $t+1^{3}$. Hence, equilibrium at $t+1$ requires

$$
X_{i t+1}=\Sigma_{h} \Sigma_{k} c_{i k}\left(1+E_{h t+1} r_{k}\right)+\varepsilon_{t+1}=\Sigma_{k} H c_{i k}\left(1+E_{t+1} r_{k}\right)+\varepsilon_{i t+1} \quad i=1 \ldots m
$$

where $E_{t+1} r_{k}=\Sigma_{h} E_{h t+1} r_{k} / H$ is the average expected return in the market for asset $k$.

Stacking the equations for different markets in vectors, the average market return at time $t+1$ must adjust (through adjustment of the current prices) to satisfy

$$
X_{t+1}=A\left(\imath+E_{t+1} r\right)+\varepsilon_{t+1}
$$

with $\imath+E_{t+1} r=\left(\left(1+E_{t+1} r_{1}\right), \ldots,\left(1+E_{t+1} r_{m}\right)\right)$ and $A=\left[a_{i k}\right]=\left[H c_{i k}\right]$, an $m \times m$ matrix.

$$
A=\left[\begin{array}{cccc}
a_{11} & a_{12} & \cdots & a_{1 m} \\
a_{21} & \ddots & & \vdots \\
\vdots & & a_{(m-1)(m-1)} & \vdots \\
a_{m 1} & \cdots & \cdots & a_{m m}
\end{array}\right]=\left[\begin{array}{cc}
A_{11} & A_{1 m} \\
A_{m 1}^{T} & a_{m m}
\end{array}\right]
$$

where $A_{11}$ is $(m-1) \times(m-1), A_{1 m}$ and $A_{m 1}$ are $(m-1) \times 1$, and $a_{m m}$ is scalar. $A$ is assumed to be a nonsingular matrix ${ }^{4}$ and can be either symmetric (with mean-variance preferences) or asymmetric. In general, $A$ has nonnegative diagonal elements (i.e. generally price sensitive traders react negatively to current price in a market, particularly so with mean-variance preferences; a decrease in the price of asset $i$ will increase the expected return of asset $i$ and

${ }^{3}$ With mean-variance preferences

$$
u\left(w_{t+2}^{h}\right)=\Sigma_{i}\left(1+E_{h t+1} r_{i}\right) x_{i t+1}^{h}-\tau \Sigma_{i} \Sigma_{j} b_{i j} x_{i t+1}^{h} x_{j t+1}^{h}
$$

$b_{i j}$ is the covariance between returns on asset $i$ and asset $j$ and $\tau$ is the common preference trade off between mean and variance of return sensitive traders. Then the $h^{t h}$ trader's demands are $x_{t+1}^{h}=\tau^{-1} B^{-1}\left(\imath+E_{h t+1} r\right)$ where $l+E_{h t+1} r$ is the $m \times 1$ vector of $h$ 's expected returns. $l$ is the $\mathrm{m} \times 1$ unit vector. $B$ is the covariance matrix of returns at time $\mathrm{t}+1$ as believed by each trader.

${ }^{4}$ Without loss of generality, if $A$ were singular we have redundant assets and can consider a smaller set of markets. 
thus increase the demand for asset $i$ ) but off diagonal elements may have an arbitrary sign.

Solving (2) for the equilibrium asset prices and returns at $t+1$

$$
\begin{aligned}
\imath+E_{t+1} r & =A^{-1} X_{t+1}-A^{-1} \varepsilon_{t+1} \\
\imath+\left(\ln \left(E P_{t+2}\right)-\ln \left(P_{t+1}\right)\right) & =A^{-1} X_{t+1}-A^{-1} \varepsilon_{t+1}
\end{aligned}
$$

(5) shows explicitly how the equilibrium prices $P_{i t+1}$ and asset returns are affected by noise trading in all markets, not only in the particular market $i$. From this market equilibrium process and the cross market effects of noise trading, we can derive the links between the first and second moments of asset prices in different markets in the next section.

Each equilibrium asset price (or return) has an explicit expression in terms of all the shocks $\varepsilon_{t+1}$ (here assumed linear for simplicity only). The asset prices or returns in (5) depend on trader expectations and generate traders expected equilibrium asset prices and returns. To convert these relations to observed realized returns we have to allow for expectation errors. More specifically, let $r_{t+1}^{T}=\left(r_{1 t+1}, r_{2 t+1}, \ldots, r_{m t+1}\right)$ be the column vector of realized returns and $\eta_{t+1}$ be the column vector of unexpected returns of $m$ asset markets at time $t+1, \eta_{t+1}^{T}=\left(\eta_{1 t+1}, \eta_{2 t+1}, \ldots, \eta_{m t+1}\right)$, where the unexpected returns $\left(\eta_{t+1}\right)=$ realized returns $\left(r_{t+1}\right)$ - expected returns $\left(E_{t+1} r\right)$. Unexpected returns are unknown at time $t+1$ and assumed to be independent across assets and iid over time (i.e. $E\left(\eta_{i t} \eta_{j t}\right)=0$ and $E\left(\eta_{i t} \eta_{i t+k}\right)=0$ ). They have mean values of zero and constant variances i.e. the variance of unexpected returns for asset $i$ is $\operatorname{var}\left(\eta_{i}\right)$. Assuming that return shocks are uncorrelated with noise trading, $E\left(\eta_{i t} \varepsilon_{i t}\right)=E\left(\eta_{i t} \varepsilon_{i t+k}\right)=0$ for all $k$. Thus, (4) is rewritten as

$$
\begin{aligned}
& r_{t+1}=A^{-1} X_{t+1}-\imath-A^{-1} \varepsilon_{t+1}+\eta_{t+1} \\
& r_{t+1}=A^{-1} X_{t+1}-\imath-A^{-1}\left(\varepsilon_{t+1}-A \eta_{t+1}\right)
\end{aligned}
$$

The actual asset returns at time $t+1, r_{t+1}$ are random.

To derive a direct relation between the observed asset returns, we can use the first $m-1$ of the relations in (6) to find $m-1$ of the noise shocks $\varepsilon_{t+1}$. Then, replacing these $m-1$ noise 
shocks in the equation for the remaining asset return gives us a linear relation between the $m$ asset returns, one of the noise shocks and the net effects of expectation errors, $\eta_{t+1}$.

Using the partitioning of markets suggested by (3) in which the first $m-1$ and the final $m^{\text {th }}$ market are distinguished, appendix 1 shows that

$$
r_{m t+1}=\frac{X_{m t+1}}{a_{m m}}-\left(\frac{A_{m 1}^{T}}{a_{m m}} l_{-m}+1\right)-\frac{A_{m 1}^{T}}{a_{m m}}\left(\left[r_{t+1}\right]_{-m}-\left[\eta_{t+1}\right]_{-m}\right)-\frac{\varepsilon_{m t+1}}{a_{m m}}+\eta_{m t+1}
$$

Where $\left[\eta_{t+1}\right]_{-m},\left[r_{t+1}\right]_{-m}$ and $\iota_{-m}$ denote the column vectors of unexpected returns and realized returns of the first $m-1$ asset markets and the $(m-1) \times 1$ unit vector, respectively. Recall that $X_{m t+1}$ is nonrandom at time $t+1$. The second term is also constant through time. This equation must hold with probability one. (7) gives us a link between observed asset returns and a single random variable which is a combination of expectation error effects and the noise shock in one market. It can explain comovements among several asset returns such as comovements between stock returns and comovements between changes in commodity prices through multi-asset portfolio investment management. It is a robust relation requiring only micro-market noise shocks and some traders who are sensitive to current asset prices in their current trading (both very weak assumptions). More detailed structure could of course be added e.g. there could be a process for underlying fundamentals which generates more detailed properties of $X_{m t+1}{ }^{5}$, but we can still derive a linear relation between asset returns and the subsequent restrictions on moments of returns following the steps below.

It is important that the price sensitive traders are trading across markets and have asset demands which react to expected returns in more than a single market. If these traders are specialists in just one market and have net demand in one market independent of the return in other markets, $A$ is a diagonal matrix. In this case, $A_{m 1}^{T}=0,(7)$ reduces to

\footnotetext{
${ }^{5}$ In addition, the expectation errors or the noise trading shocks could take a more complicated form e.g. the expectation errors or the noise trading shocks may be autocorrelated.
} 


$$
r_{m t+1}=\frac{X_{m t+1}}{a_{m m}}-\frac{\varepsilon_{m t+1}}{a_{m m}}+\eta_{m t+1}-1
$$

and there is no systematic relation between asset returns in different markets.

\section{Equilibrium Moment Restrictions}

\subsection{First Moments}

Taking expectations over $\varepsilon_{t+1}$ and $\eta_{t+1}$ in (7), the first moment is

$$
E_{t+1} r_{m t+1}=\frac{X_{m t+1}}{a_{m m}}-\left(\frac{A_{m 1}^{T}}{a_{m m}} \iota_{-m}+1\right)-\frac{A_{m 1}^{T}}{a_{m m}}\left[E_{t+1} r_{t+1}\right]_{-m}-\frac{\mu_{m t+1}}{a_{m m}}
$$

Note that this is more general than the equivalent restriction coming from a single factor model e.g. CAPM or from a multi-factor model with less than $m$ factors e.g. a three-factor model of Fama and French (1993) or a recently developed factor model of Bekaert et al. (2005). More precisely, in CAPM the excess return on each asset is a linear function of the market excess return so that whilst certainly there is then a linear relation between expected excess returns on individual assets, (9) could hold even if there are $m-1$ factors. In the international CAPM the expected return of the $i^{\text {th }}$ market depends on the US asset returns only, but here the expected return of the $i^{\text {th }}$ market can be affected by the expected return of other markets. This supports the finding of Mukherjee and Misha (2010) that daily Indian stock returns are affected by contemporaneous daily returns of some Asian stock markets.

\subsection{Second Moments}

From (6) the covariance matrix of asset returns at equilibrium is $\Lambda$

$$
\Lambda=A^{-T} \Sigma A^{-1}
$$

where the covariance matrix of random shocks to returns is

$$
\Sigma=\left[\begin{array}{cccc}
\gamma_{11}+\sum_{i=1}^{m} a_{i 1}^{2} \operatorname{var}\left(\eta_{i}\right) & \gamma_{12}+\sum_{i=1}^{m} a_{i 1} a_{i 2} \operatorname{var}\left(\eta_{i}\right) & \cdots & \gamma_{1 m}+\sum_{i=1}^{m} a_{i 1} a_{i m} \operatorname{var}\left(\eta_{i}\right) \\
\gamma_{12}+\sum_{i=1}^{m} a_{i 1} a_{i 2} \operatorname{var}\left(\eta_{i}\right) & \gamma_{22}+\sum_{i=1}^{m} a_{i 2}^{2} \operatorname{var}\left(\eta_{i}\right) & & \vdots \\
\vdots & \cdots & \ddots & \vdots \\
\gamma_{1 m}+\sum_{i=1}^{m} a_{i 1} a_{i m} \operatorname{var}\left(\eta_{i}\right) & \cdots & \gamma_{m m}+\sum_{i=1}^{m} a_{i m}^{2} \operatorname{var}\left(\eta_{i}\right)
\end{array}\right]
$$

Partition the markets into the first $m-1$ and the last so the covariance matrix of random shocks 


$$
\Sigma=\left[\begin{array}{cc}
\Sigma_{11} & \Sigma_{1 m} \\
\Sigma_{1 m}^{T} & \Sigma_{m m}
\end{array}\right]
$$

Here $\Sigma_{11}$ is $(m-1) \times(m-1), \Sigma_{1 m}$ is the $(m-1) \times 1$ column vector of covariance between random shock in the $m^{\text {th }}$ asset market and that in other asset markets, and $\Sigma_{m m}$ is scalar equal to $\gamma_{m m}+\sum_{i=1}^{m} a_{i m}^{2} \operatorname{var}\left(\eta_{i}\right)$

Likewise, partition the covariance matrix of returns into the first $m-1$ and the last so

$$
\Lambda=\left[\begin{array}{cc}
\Lambda_{11} & \Lambda_{1 m} \\
\Lambda_{1 m}^{T} & \Lambda_{m m}
\end{array}\right]
$$

$\Lambda_{11}$ is $(m-1) \times(m-1)$ and $\Lambda_{1 m}$ is the column vector $(m-1) \times 1$ of the covariance between the return of the $m^{\text {th }}$ asset and other asset returns. $\Lambda_{m m}$ is the variance of the $m^{\text {th }}$ asset return, so it is scalar. Let the inverse of the matrix $A$ be

So

$$
A^{-1}=\left[\begin{array}{cc}
\alpha_{11} & \alpha_{1 m} \\
\alpha_{m 1}^{T} & \alpha_{m m}
\end{array}\right]_{m x m}
$$

$$
\left[\begin{array}{cc}
\Lambda_{11} & \Lambda_{1 m} \\
\Lambda_{1 m}^{T} & \Lambda_{m m}
\end{array}\right]=\left[\begin{array}{ll}
\alpha_{11}^{T} & \alpha_{m 1} \\
\alpha_{1 m}^{T} & \alpha_{m m}
\end{array}\right]\left[\begin{array}{cc}
\Sigma_{11} & \Sigma_{1 m} \\
\Sigma_{1 m}^{T} & \Sigma_{m m}
\end{array}\right]\left[\begin{array}{cc}
\alpha_{11} & \alpha_{1 m} \\
\alpha_{m 1}^{T} & \alpha_{m m}
\end{array}\right]
$$

Thus, the covariance matrix of asset returns (see appendix 2) satisfies

$$
\begin{aligned}
\Lambda_{1 m}= & \left(I-\frac{\alpha_{m 1} \alpha_{1 m}^{T} \alpha_{11}^{-T}}{\alpha_{m m}+\alpha_{m 1}^{T} \alpha_{11}^{-1} \alpha_{1 m}}\right) \Lambda_{11} \alpha_{11}^{-1} \alpha_{1 m}+\frac{\alpha_{m 1}}{\alpha_{m m}+\alpha_{m 1}^{T} \alpha_{11}^{-1} \alpha_{1 m}} \Lambda_{m m} \\
& +\left(\alpha_{11}^{T}-\frac{2 \alpha_{m 1} \alpha_{1 m}^{T}}{\alpha_{m m}+\alpha_{m 1}^{T} \alpha_{11}^{-1} \alpha_{1 m}}\right) \Sigma_{1 m}\left(\alpha_{m m}-\alpha_{m 1}^{T} \alpha_{11}^{-1} \alpha_{1 m}\right)
\end{aligned}
$$

As the $\Gamma$ matrix and $\operatorname{var}\left(\eta_{i}\right)$ are not time-varying, the last term is a constant intercept. (10) is a key theoretical result of this paper. It shows that there are $m-1$ linear restrictions between elements of the covariance matrix of asset returns that subsequently we can specialize to suit a variety of contexts depending on the parameters in the matrix $A$, which are set behaviorally by the context in which the flow traders operate. The moment restriction (10) shows that the covariance between asset returns in two markets is not only affected by their own variances, but also by variances and covariances of asset returns in the other markets, reflected in $\Lambda_{11}$ the covariance matrix of the first $m$ - 1 assets. Note that some elements 
of the matrix $I-\alpha_{m 1} \alpha_{1 m}^{T} \alpha_{11}^{-T} /\left(\alpha_{m m}+\alpha_{m 1}^{T} \alpha_{11}^{-1} \alpha_{1 m}\right)$ can be zero.

In the case that the trading shocks in the last market $\left(\varepsilon_{m t+1}\right)$ are uncorrelated with those of other markets $\left(\varepsilon_{i t+1}\right.$ for $\left.i \neq m\right)$ i.e. $\gamma_{i m}=0$, and flow traders in all markets are specialists (i.e. $\alpha_{1 m}$ and $\alpha_{m 1}$ are null vectors and $A_{11}$ and $\alpha_{11}$ are diagonal matrices), both $\Sigma_{1 m}$ and $\Lambda_{1 m}$ become null vectors. Note that the intercept in (10) being zero does not always imply that $\Sigma_{1 m}=0$. Or, if all flow traders are specialists but the trading shocks in the last market are correlated with those of other markets, then $\Sigma_{1 m}$ is not a null vector and

Summarising

$$
\begin{aligned}
\Lambda_{1 m} & =\alpha_{11} \Sigma_{1 m} \alpha_{m m} \\
& =A_{11}^{-1} \Sigma_{1 m} \alpha_{m m}
\end{aligned}
$$

Proposition 1 There are $m-1$ linear restrictions between the variances and covariances of equilibrium risky asset returns. The intercept involves the covariance between markets of the fundamental shocks and sensitivity of flow traders' demands to all asset returns. Whether the comovement between two asset returns will be affected by the volatility and co-movement of other asset markets depends on whether flow traders' demand for those particular two assets is sensitive to asset returns in the other markets.

Here, we have not explicitly identified a safe asset, but if one of the $m$ assets has a safe return $r_{f}$, the same framework leads to a similar relationship between the returns of $m-1$ risky assets and a risk-free rate. Thus, (7) still holds. That is, if the risk-free asset is the $1^{\text {st }}$ asset, $r_{1 t+1}$ in (6) becomes $r_{f}$. Since the risk-free rate is non-random, $\eta_{1 t+1}=0_{\text {which yields }}$

$$
r_{m t+1}=\frac{X_{m t+1}}{a_{m m}}-\left(\frac{A_{m 1}^{T}}{a_{m m}} l_{-m}+1\right)-\frac{a_{m 1}}{a_{m m}}\left[r_{f}\right]-\frac{A_{(m-1) 1}^{T}}{a_{m m}}\left(\left[r_{t+1}\right]_{-m-1}-\left[\eta_{t+1}\right]_{-m-1}\right)-\frac{\varepsilon_{m t+1}}{a_{m m}}+\eta_{m t+1}
$$

where $A_{(m-1) 1}^{T}=\left[\begin{array}{lll}a_{m 2} & \ldots & a_{m, m-1}\end{array}\right],\left[r_{t+1}\right]_{-m-1}=\left[\begin{array}{lll}r_{2 t+1} & \ldots & r_{(m-1) t+1}\end{array}\right]$ and $\left[\eta_{t+1}\right]_{-m-1}$ $=\left[\begin{array}{lll}\eta_{2 t+1} & \ldots & \eta_{(m-1) t+1}\end{array}\right]$. Then, there will be $m-2$ linear restrictions between the variances and covariances of risky asset returns. 
If flow traders respond to the excess returns $r_{i}^{e}$ of $m$ risky assets instead of their expected return, then $E_{t+1} r^{e}=r_{t+1}-r_{f}-\eta_{t+1}$. Consequently, the relationship between $m$ risky asset returns is

$$
r_{m t+1}=r_{f}+\frac{A_{m 1}^{T}}{a_{m m}}\left[r_{f}\right]_{-m}+\frac{X_{m t+1}}{a_{m m}}-\left(\frac{A_{m 1}^{T}}{a_{m m}} l_{-m}+1\right)-\frac{A_{m 1}^{T}}{a_{m m}}\left(\left[r_{t+1}\right]_{-m}-\left[\eta_{t+1}\right]_{-m}\right)-\frac{\varepsilon_{m t+1}}{a_{m m}}+\eta_{m t+1}
$$

where $\left[r_{f}\right]_{-m}$ is the $(m-1) \times 1$ column vector of constants equal to the risk free rate. If $r_{f}$ is non-random, then the first two terms of (13) are nonrandom and there is a set of $m-1$ moment restrictions which is still (7) with variances and covariances of asset returns.

\section{A Comparison with Alternative Models}

Alternative models to explain the asset returns and their inter-relations typically use more structure than we do. Some models start with an exogenous process for an underlying set of equilibrium prices which are sometimes driven by processes on fundamentals, we do not have to impose these assumptions.

Although CAPM is still a widely used framework in which the expected excess return on each individual asset depends on a single common factor (the expected excess return on the market), it offers little to explain more complicated links between the covariances of different pairs of assets. Compared to CAPM which requires a safe rate and assumes that traders have mean-variance expected utility and only differ in risk aversion and not in their views of mean, variances and covariance of returns, our framework does not require these assumptions. In terms of results, CAPM is a one factor model which relates the individual asset expected excess returns to the expected excess return on the market portfolio, while our approach allows empirical investigation of the individual effects of asset returns.

In particular, CAPM does not develop links between second moments of more than two individual assets. In CAPM, $E r_{i}-r_{f}=\alpha_{i}+\beta_{i}\left(E R_{m}-r_{f}\right)$ so for any pair of individual returns of assets $i$ and $j$ 


$$
E r_{i}-r_{f}=\alpha_{i}+\frac{\beta_{i}}{\beta_{j}}\left(E r_{j}-r_{f}-\alpha_{j}\right)
$$

By treating the $\alpha$ and $\beta$ as constants, CAPM implies a linear relation between mean excess returns on two different assets but not on their second moments. As

$$
\beta_{i}=\frac{\operatorname{cov}\left(r_{i}-r_{f}, r_{m}-r_{f}\right)}{\operatorname{var}\left(r_{m}-r_{f}\right)}=\frac{\operatorname{cov}\left(r_{i}, r_{m}\right)}{\operatorname{var}\left(r_{m}\right)},
$$

(14) can also be viewed as a relation between mean excess returns and the ratio of covariances of two asset returns with the market. We could also rewrite CAPM as $r_{i}-r_{f}=\alpha_{i}+\beta_{i}\left(R_{m}-r_{f}\right)+\eta_{i}$ where $\eta_{i}$ is the unexpected return of asset $i$ and obtain $\operatorname{cov}\left(r_{i}-r_{f}, r_{j}-r_{f}\right)=\beta_{i} \beta_{j} \operatorname{var}\left(R_{m}\right)+\operatorname{cov}\left(\eta_{i}, \eta_{j}\right)$. Then, the covariances of returns between any pair of individual assets will be proportional to the variance of the return on the market if the idiosyncratic shocks on assets are independent (which is commonly assumed). Thus, CAPM implies (9) but is not implied by it.

A more general alternative than CAPM is the multi-factor model. Suppose for an example we take a two-factor model in which the return on any asset can be written as

$$
r_{i t+1}=\beta_{i}+\alpha_{1 i} F_{1 t+1}+\alpha_{2 i} F_{2 t+1}+\varepsilon_{i t+1}
$$

where $F_{j}$ are factors and $\varepsilon_{i}$ are random with zero mean. Taking any two assets (say the first two assets) we can solve for the factors in terms of the returns on the first two assets

$$
\left[\begin{array}{l}
F_{1} \\
F_{2}
\end{array}\right]=\left[\begin{array}{ll}
\omega_{11} & \omega_{12} \\
\omega_{21} & \omega_{22}
\end{array}\right]\left[\begin{array}{l}
r_{1}-\beta_{1}-\varepsilon_{1} \\
r_{2}-\beta_{2}-\varepsilon_{2}
\end{array}\right]
$$

and then replacing this in $(15)$ gives $^{6}$

$$
r_{i}=\beta_{i}^{\prime}+\alpha_{i 1}^{\prime} r_{1}+\alpha_{i 2}^{\prime} r_{2}+\lambda_{i 1} \varepsilon_{1}+\lambda_{i 2} \varepsilon_{2}+\varepsilon_{i}, i=3 \ldots m
$$

This gives us a relation between the returns on any three assets but since there are only two

6

$$
\begin{aligned}
r_{i} & =\beta_{i}+\alpha_{1 i}\left[\omega_{11}\left(r_{1}-\beta_{1}-\varepsilon_{1}\right)+\omega_{12}\left(r_{2}-\beta_{2}-\varepsilon_{2}\right)\right]+\alpha_{2 i}\left[\omega_{21}\left(r_{1}-\beta_{1}-\varepsilon_{1}\right)+\omega_{22}\left(r_{2}-\beta_{2}-\varepsilon_{2}\right)\right]+\varepsilon_{i} \\
& =\beta_{i}^{\prime}+\alpha_{i 1} r_{1}+\alpha_{i 2}^{\prime} r_{2}+\lambda_{i 1} \varepsilon_{1}+\lambda_{i 2} \varepsilon_{2}+\varepsilon_{i}
\end{aligned}
$$


factors involved, the restrictions which can be derived on second moments of asset returns are more limited.

A sophisticated example of this two-factor approach is in Bekaert et al. (2005) who identify the two factors with respectively the return on the US market and the return on a regional market to which the $i^{\text {th }}$ asset belongs e.g. an Asian market index for an asset traded in Singapore. In their approach, the covariance between asset returns in the $i^{\text {th }}$ market and the US market is only explained by the volatility of US asset returns, and the covariances between asset returns in the $i^{\text {th }}$ market and the $j^{\text {th }}$ market (or the regional market) are only determined by the volatilities of US and regional stock index returns. However, they do not capture more detailed links between the covariances of individual asset returns trading either in the same or different regions. With our approach, relationships of second moments can be derived between various individual asset returns, between market returns in different countries and regions, and between individual asset returns and market returns of their own country (region), as well as market returns of other countries and regions.

Moreover, our framework can also explain how asset correlations react to the contagious effects of crises. Within a normal time period, the short-term traders' sensitivity to asset returns is unchanged. However, in a crisis period, traders may become more sensitive to some markets but choose not to invest in other markets. Karolyi (2002) finds that before the 1997 Asian financial crisis foreign investors were net buyers of Japanese equity, but they became net sellers during the Asian crisis in 1997 and 1998.

Bekaert and Harvey (2003) find that during the Asian financial crisis not only did Asian countries experience lowest returns, but Turkey and some Latin American countries e.g. Brazil, Chile, Venezuela, Columbia also faced the lowest returns in that specific time. Coincidence of extreme equity movements may be evidence of contagion. In the David Finch lecture at the IMF in 1998, Fischer pointed out that a cause of the turbulence in international capital markets during a crisis is the dependence between markets that allows market shocks 
in an individual market to spillover onto other markets. Some researchers explain that comovements in financial asset prices result from real and financial linkages among market economies while contagion involving financial crises may not necessarily be linked to macroeconomic or other fundamental factors but to the behavior of investors often referred as 'irrational contagion'. Karolyi (2003) suggests that international financial contagion can be associated with financial panic, herd behavior, loss of confidence, increases in risk aversion, imperfect information and differences in investor expectations. For example, if the crisis reflects weak fundamentals of one country, investors may rationally conclude that similar countries have similar problems, and thus crisis in one country may lead to an attack on the assets of another country. The contagious effect of crisis may be due to changes in expectations that are self-fulfilling in markets with multiple equilibria. Less well-informed investors could adjust their portfolios following investors who have acted earlier. Some investors may suddenly withdraw investments from the crisis market if they fear that they will be too late to have a claim on a limited asset pool if they do not. This indicates that investors' sensitivity to asset returns in the normal and crisis periods can be different; therefore, the elements of matrix $A$ can change in a particular period like a crisis. For example, $A$ in the mean-variance framework is $H \tau^{-1} B^{-1}$. While the volatility of returns are stable during the normal period, a shift in the perceived variances or covariances of returns (elements in the $B$ matrix) or changes in investors' preference $\tau$ during the crisis can result in changes in investors sensitivity to asset returns i.e. the elements of $A$.

\section{A special case with two assets}

To see the detail of these restrictions in terms of the impact of flow traders on markets, we take an example with only two risky assets. If the intercept is zero, a lower bound on price correlation can be derived. With only specialists trading in the market, there are no moment restrictions between asset returns, but the determinants of variances and covariance are still found. 


\subsection{Moment Restrictions}

There are two assets $(m=2)$ and the long-term investors can either long or short the assets at time $t+1$. The $h^{\text {th }}$ flow trader net demand in market $i$ is responsive to expected returns in both markets: $f_{i}^{h}\left(1+E_{h t+1} r_{1}, 1+E_{h t+1} r_{2}\right)=\Sigma_{k=1}^{2} c_{i k}\left(1+E_{h t+1} r_{k}\right)$.

$$
A=\left[\begin{array}{ll}
a_{11} & a_{12} \\
a_{21} & a_{22}
\end{array}\right]
$$

The variance-covariance matrix of random shocks is

$$
\Sigma=\left[\begin{array}{cc}
\gamma_{11}+a_{11}^{2} \operatorname{var}\left(\eta_{1}\right)+a_{21}^{2} \operatorname{var}\left(\eta_{2}\right) & \gamma_{12}+a_{11} a_{12} \operatorname{var}\left(\eta_{1}\right)+a_{21} a_{22} \operatorname{var}\left(\eta_{2}\right) \\
\gamma_{12}+a_{11} a_{12} \operatorname{var}\left(\eta_{1}\right)+a_{21} a_{22} \operatorname{var}\left(\eta_{2}\right) & \gamma_{22}+a_{12}^{2} \operatorname{var}\left(\eta_{1}\right)+a_{22}^{2} \operatorname{var}\left(\eta_{2}\right)
\end{array}\right]
$$

is $2 \times 2$. (10) becomes

$$
\begin{aligned}
\lambda_{12}= & \left(1-\frac{\alpha_{21} \alpha_{12} \alpha_{11}^{-1}}{\alpha_{22}+\alpha_{21} \alpha_{11}^{-1} \alpha_{12}}\right) \lambda_{11} \alpha_{11}^{-1} \alpha_{12}+\frac{1}{\alpha_{22}+\alpha_{21} \alpha_{11}^{-1} \alpha_{12}} \alpha_{21} \lambda_{22} \\
& +\left(\alpha_{22}-\alpha_{21} \alpha_{11}^{-1} \alpha_{12}\right)\left(\alpha_{11}-\frac{2 \alpha_{21} \alpha_{12}}{\alpha_{22}+\alpha_{21} \alpha_{11}^{-1} \alpha_{12}}\right)\left[\gamma_{12}+a_{11} a_{12} \operatorname{var}\left(\eta_{1}\right)+a_{21} a_{22} \operatorname{var}\left(\eta_{2}\right)\right]
\end{aligned}
$$

which can be written as

$$
\begin{aligned}
\lambda_{12}= & \frac{\alpha_{22} \alpha_{12}}{\alpha_{11} \alpha_{22}+\alpha_{21} \alpha_{12}} \lambda_{11}+\frac{\alpha_{11} \alpha_{21}}{\alpha_{11} \alpha_{22}+\alpha_{21} \alpha_{12}} \lambda_{22} \\
& +\frac{\left(\alpha_{11} \alpha_{22}-\alpha_{21} \alpha_{12}\right)^{2}}{\alpha_{11} \alpha_{22}+\alpha_{21} \alpha_{12}}\left[\gamma_{12}+a_{11} a_{12} \operatorname{var}\left(\eta_{1}\right)+a_{21} a_{22} \operatorname{var}\left(\eta_{2}\right)\right]
\end{aligned}
$$

Recall that the $\alpha_{i j}$ are elements of the inverse of $A$ :

$$
\begin{gathered}
A^{-1}=\left[\begin{array}{ll}
\alpha_{11} & \alpha_{12} \\
\alpha_{21}^{T} & \alpha_{22}
\end{array}\right]_{2 \times 2} \\
\alpha_{11}=\frac{a_{22}}{a_{11} a_{22}-a_{12} a_{21}}, \alpha_{22}=\frac{a_{11}}{a_{11} a_{22}-a_{12} a_{21}}, \alpha_{12}=\frac{-a_{12}}{a_{11} a_{22}-a_{12} a_{21}}, \alpha_{21}=\frac{-a_{21}}{a_{11} a_{22}-a_{12} a_{21}}
\end{gathered}
$$

so (17) becomes

$$
\lambda_{12}=-\frac{a_{11} a_{12}}{a_{22} a_{11}+a_{12} a_{21}} \lambda_{11}-\frac{a_{22} a_{21}}{a_{22} a_{11}+a_{12} a_{21}} \lambda_{22}+\frac{\left[\gamma_{12}+a_{11} a_{12} \operatorname{var}\left(\eta_{1}\right)+a_{21} a_{22} \operatorname{var}\left(\eta_{2}\right)\right]}{\left(a_{22} a_{11}+a_{12} a_{21}\right)}
$$

For the special case in which $\gamma_{12}+a_{11} a_{12} \operatorname{var}\left(\eta_{1}\right)+a_{21} a_{22} \operatorname{var}\left(\eta_{2}\right)=0$, the restriction becomes

$$
\lambda_{12}=-\frac{a_{11} a_{12}}{a_{11} a_{22}+a_{12} a_{21}} \lambda_{11}-\frac{a_{21} a_{22}}{a_{11} a_{22}+a_{12} a_{21}} \lambda_{22}
$$

Recall that $a_{j j}>0$ but $a_{j k}$ is of ambiguous sign. The denominator is positive if $a_{j k}$ and 
$a_{j k}$ have the same sign. If $a_{j k}>0$ which could occur with strong complementarities for flow traders, then the covariance could be negative. However, in the more likely case $a_{j k}<0$ and $\lambda_{12}>0$; also, an increase in the volatility of the asset markets can increase the covariance.

Another special case arises when the flow traders are specialists responding to the expected return in only one market $\left(a_{j k}=0\right)$ in which case

$$
\lambda_{11}=\frac{\gamma_{11}}{a_{11}^{2}}+\operatorname{var}\left(\eta_{1}\right), \lambda_{22}=\frac{\gamma_{22}}{a_{22}^{2}}+\operatorname{var}\left(\eta_{2}\right), \lambda_{12}=\frac{\gamma_{12}}{a_{11} a_{22}}
$$

and there is then no second moment restriction. The magnitude of liquidity shocks and unexpected returns totally determines the volatility of asset returns.

\subsection{Lower Bound of Correlation}

There is also an implicit lower bound on the absolute value of the correlation $|\rho|$ between the asset returns when $\gamma_{12}=-a_{11} a_{12} \operatorname{var}\left(\eta_{1}\right)-a_{21} a_{22} \operatorname{var}\left(\eta_{2}\right)$ and flow traders are generalists. From (18)

$$
\begin{aligned}
\lambda_{12}^{2} & =\left(-\frac{a_{11} a_{12}}{a_{11} a_{22}+a_{12} a_{21}} \lambda_{11}-\frac{a_{21} a_{22}}{a_{11} a_{22}+a_{12} a_{21}} \lambda_{22}\right)^{2} \\
& =\left(-\frac{a_{11} a_{12}}{a_{11} a_{22}+a_{12} a_{21}}\right)^{2} \lambda_{11}^{2}+\left(-\frac{a_{21} a_{22}}{a_{11} a_{22}+a_{12} a_{21}}\right)^{2} \lambda_{22}^{2}+2 \frac{a_{11} a_{12} a_{21} a_{22}}{\left(a_{11} a_{22}+a_{12} a_{21}\right)^{2}} \lambda_{11} \lambda_{22}
\end{aligned}
$$

So

$$
\rho^{2}=\lambda_{12}^{2} / \lambda_{11} \lambda_{22}=\left(\frac{a_{11} a_{12}}{a_{11} a_{22}+a_{12} a_{21}}\right)^{2} \lambda_{11} / \lambda_{22}+\left(\frac{a_{21} a_{22}}{a_{11} a_{22}+a_{12} a_{21}}\right)^{2} \lambda_{22} / \lambda_{11}+2 \frac{a_{11} a_{12} a_{21} a_{22}}{\left(a_{11} a_{22}+a_{12} a_{21}\right)^{2}}
$$

The absolute value of the correlation depends on relative variances and flow traders' sensitivities to both asset returns. But since the first two terms are positive,

$$
\rho^{2}>2 \frac{a_{11} a_{22} a_{12} a_{21}}{\left(a_{11} a_{22}+a_{12} a_{21}\right)^{2}},
$$

The squared correlation between asset returns is bounded below by the right hand side; equivalently,

$$
|\rho|>\frac{\sqrt{2 a_{11} a_{22} a_{12} a_{21}}}{\left(a_{11} a_{22}+a_{12} a_{21}\right)}
$$


That is, the absolute value of the correlation between the asset returns has a lower bound depending on flow traders' sensitivities to both asset returns only.

Summarising

Proposition 2 An implicit lower bound on the absolute value of the correlation $|\rho|$ between the asset returns is found when $\gamma_{12}=-a_{11} a_{12} \operatorname{var}\left(\eta_{1}\right)-a_{21} a_{22} \operatorname{var}\left(\eta_{2}\right)$ and flow traders are generalists. The lower bound of correlation depends on flow traders' sensitivities to both asset returns, and is independent of variances of asset returns.

\section{Some Empirical Evidence}

The theory above predicts that there should be a linear restriction between asset returns at any time:

$$
r_{m t+1}=\frac{X_{m t+1}}{a_{m m}}-\left(\frac{A_{m 1}^{T}}{a_{m m}} l_{-m}+1\right)-\frac{A_{m 1}^{T}}{a_{m m}}\left[r_{t+1}\right]_{-m}-\frac{\varepsilon_{m t+1}}{a_{m m}}+\frac{A_{m 1}^{T}}{a_{m m}}\left[\eta_{t+1}\right]_{-m}+\eta_{m t+1}
$$

and $r_{t+1}=A^{-1} X_{t+1}-\imath-A^{-1}\left(\varepsilon_{t+1}-A \eta_{t+1}\right)$ from which we deduce $m-1$ linear restrictions between the second moments of market returns at any time:

$$
\begin{aligned}
\Lambda_{1 m}= & \left(I-\frac{\alpha_{m 1} \alpha_{1 m}^{T} \alpha_{11}^{-T}}{\alpha_{m m}+\alpha_{m 1}^{T} \alpha_{11}^{-1} \alpha_{1 m}}\right) \Lambda_{11} \alpha_{11}^{-1} \alpha_{1 m}+\frac{\alpha_{m 1}}{\alpha_{m m}+\alpha_{m 1}^{T} \alpha_{11}^{-1} \alpha_{1 m}} \Lambda_{m m} \\
& +\left(\alpha_{11}^{T}-\frac{2 \alpha_{m 1} \alpha_{1 m}^{T}}{\alpha_{m m}+\alpha_{m 1}^{T} \alpha_{11}^{-1} \alpha_{1 m}}\right) \Sigma_{1 m}\left(\alpha_{m m}-\alpha_{m 1}^{T} \alpha_{11}^{-1} \alpha_{1 m}\right)
\end{aligned}
$$

Given data on the second moments of market returns $\Lambda_{i j}$ we want to test if these restrictions hold. If the restrictions are valid, there should be a stable time series regression between the monthly second moment series. We would not expect this relation to be exact partly because of many omitted effects e.g. measurement errors arising in computing the sample of second moments, timing differences between markets, and lack of synchronization of trade in markets for different assets. So adding disturbances to each equation at each sample point gives a seemingly unrelated regression system. If there is a stable linear relationship over time and mean values of disturbances are very close to zero, there is strong evidence in favor of the restrictions we highlight and the existence of a nondiagonal $A$ matrix. 
Here, we take monthly data on stock returns in three developed market (UK FTSE100 index (F), Japanese Nikkei225 index (N), and US DJIA index (D)) and stock returns in three emerging markets (China's SSE index (C), India's Bombay Stock Exchange (BSE) 100 index $(\mathrm{I})^{7}$, and Russia's AKM Composite index $\left.(\mathrm{R})^{8}\right)$. The data covers the period from October 1993 to May 2012; this period includes the 1997-1998 Asian financial crisis period which is between July 1997-July 1999 and the 2008-2012 global financial crisis period which is from September 2008 onwards. This allows us to test whether the elements of the matrix $A$ change in some periods, especially periods of crisis. For each market we compute the monthly variance and covariances of returns ${ }^{9}$. This gives us a monthly sample of elements of $\Lambda$ which then vary month by month, but are stationary (see Table 3 in Appendix). For each monthly second moment we have 224 observations.

We take the DJIA as the $m^{\text {th }}$ asset in our theoretical framework, allowing our framework to be compared with others using the US market as a proxy of the world market. (10) can be thought of as a system of equations in which each element of $\Lambda_{16}$ (the covariances of the DJIA index return with the other stock index returns) is expressed in terms of $\Lambda_{66}$ (the variance of the DJIA index return: $\sigma_{D}^{2}$ ) and all the elements of $\Lambda_{11}$ (the variances and covariances of the other stock index returns) together with a constant term which reflects the impact of $\Sigma_{16}$. To form the dependent variables, we stack the observations on the elements of $\Lambda_{16}$ in the column $Y$ (so the first 224 elements of $Y$ correspond to the sample observations on the first covariance in $\Lambda_{16}$, the next 224 to the second covariance and so on).

\footnotetext{
7 The Bombay Stock Exchange (BSE) 100 index is a broad based stock index. It has 1984 as the base year and was launched in 1989. It's composed of top 100 constituents listed in the Bombay Stock exchanges in Mumbai, regarded as the oldest stock market in Asia.

${ }^{8}$ The AKM composite index is a market value-weighted index of capitalisation of all stocks listed in the Russian stock market with the base date on September 1, 1993.

9 The monthly variance of returns is its variance across weeks in the month. Thus, our sample variances and covariances are calculated without nonoverlapping data periods.
} 


$$
Y=\left[\begin{array}{l}
Y_{1} \\
Y_{2} \\
Y_{3} \\
Y_{4} \\
Y_{5}
\end{array}\right]=\left[\begin{array}{l}
{\left[\sigma_{F D}\right]_{224 \times 1}} \\
{\left[\sigma_{N D}\right]_{224 \times 1}} \\
{\left[\sigma_{C D}\right]_{224 \times 1}} \\
{\left[\sigma_{I D}\right]_{224 \times 1}} \\
{\left[\sigma_{R D}\right]_{224 \times 1}}
\end{array}\right]
$$

Let $X$ be the $224 \times 17$ regressor matrix with each column containing the sample observations on one of 15 elements in $\Lambda_{11}$, the observations on $\Lambda_{66}$ and a constant term. Thus, the elements of matrix $X$ are $\sigma_{i j}$ denoting the covariance between asset returns in market $i$ and $j, \sigma_{i}^{2}$ denoting the variance of asset return in market $i$ and the constant term. According to (10), the coefficients in the equations of the variables in $\Lambda_{11}$ and $\Lambda_{66}$ are combinations of elements of the inverse of $A$. So

$$
X=\left[\begin{array}{ccccc}
\sigma_{F, \text { Oct } 93}^{2} & \cdots & \sigma_{I R, \text { Oct } 12} & \sigma_{D, \text { Oct93 }}^{2} & 1 \\
\vdots & \ddots & \vdots & \vdots & \vdots \\
\sigma_{F, \text { May } 12}^{2} & & \sigma_{I R, \text { May } 12} & \sigma_{D, \text { May } 12}^{2} & 1
\end{array}\right]
$$

There are 5 equations in the second moment restriction regression system with the six stock returns. The regression system is

$$
Y=(I \otimes X) \beta+\varepsilon ; \beta=\left[\begin{array}{c}
\beta_{1} \\
\vdots \\
\beta_{5}
\end{array}\right] ; \beta_{i}=\left[\begin{array}{c}
\phi_{i} \\
\delta_{i} \\
\theta_{i}
\end{array}\right] ; \varepsilon=\left[\begin{array}{c}
\varepsilon_{1} \\
\vdots \\
\varepsilon_{5}
\end{array}\right]
$$

where $E \varepsilon_{i}=0, E \varepsilon_{i} \varepsilon_{i}^{\prime}=\Omega_{i}$. Here $\phi_{i}$ is a column of the 15 regression coefficients of the elements of $\Lambda_{11}$ in the $i^{\text {th }}$ equation, $\delta_{i}$ is the coefficient of $\sigma_{D}^{2}$ and $\theta_{i}$ is the estimated constant term in each equation. $\Omega_{i}$ is the contemporaneous covariance matrix of the disturbances on the $i^{\text {th }}$ equation, assumed to be constant through time. Even if there is correlation between the disturbances of different equations, the coefficients obtained from OLS estimation applied to each equation of the system in turn still yields an efficient estimator since the regressors in each equation are identical and stationary (see the unit root test results shown in Table 3 in Appendix). Written equation by equation, the dependent variables are $\sigma_{i D}$ and the $i^{t h}$ equation is 


$$
\sigma_{i D}=X \beta_{i}+\varepsilon_{i}
$$

The results of this exercise are shown in Table 1, which uses White's Heteroskedasticity-consistent standard errors and covariances. The columns give the summary results for each of the five equations. First we estimate each equation of the system above and find that Ramsey's regression specification error test (RESET) result indicates mis-specification in all equations (see Table 4 in Appendix). Then, we investigate the data and find that the root of the problem is structural breaks during the 1997 Asian financial crisis and the recent financial crisis. Therefore, we add two dummy variables and their interaction with the variances and covariances into the system. The first dummy variable is $A F C$ with the value 1 for the observations during the period July 1997 - July 1999 and 0 otherwise. The second dummy variable is $G F C$ with the value 0 for the observations before September 2008 and 1 for the observations after September 2008. Panel A in Table 1 gives estimators of $\beta_{i}, \gamma_{i}$ and $\theta_{i}$. Panel B provides the coefficients of $A F C$ and its interaction terms and Panel $\mathrm{C}$ contains coefficients of $G F C$ and its interaction terms.

Significance of some or all coefficients of covariance terms in the model implies that our framework is valid - that is, covariances of asset returns can be explained not only by variance terms but also by other covariances. A change in the $A$ matrix can also explain changes in intercepts and slope coefficients in crisis periods. Significance of coefficients in Panel $\mathrm{B}$ and $\mathrm{C}$ indicates that trader's sensitivity to asset returns changes during crises. The sum of coefficients of each regressor in Panel A and its interaction terms in Panel B (Panel C) is the effect of each regressor on the covariance of market $i$ with DJIA during the Asian financial crisis (Global financial crisis)

The result supports our theoretical finding that the covariance between any two index returns depends not only on the volatilities of the returns, but also volatilities in other markets and covariances among markets. Regarding Panel A, except for the covariance between DJIA and SSE, all covariances between DJIA and other index returns depend on not only the 
volatility of DJIA as suggested by the framework of Bekaert et al. (2005), but also variances and covariances of the four asset returns: FTSE, Nikkei225, BSE100 and AKM. More specifically, covariances of FTSE100 and AKM with DJIA $\left(\sigma_{F D}, \sigma_{R D}\right)$ depend on not only the volatility of DJIA, but also their own volatilities. In addition, $\sigma_{R D}$ is also affected by the covariance between FTSE100 and AKM $\left(\sigma_{F R}\right)$. For the Nikkei225 and BSE100, their covariances with DJIA depend on the volatilities of FTSE and DJIA, but do not depend on their own volatility. The covariance of Nikkei225 with DJIA $\left(\sigma_{N D}\right)$ also depends on the covariance between FTSE100 and Nikkei225 $\left(\sigma_{F N}\right)$ and the volatility of BSE100 $\left(\sigma_{I}^{2}\right)$ while the covariance of BSE100 with DJIA $\left(\sigma_{I D}\right)$ depends on covariances between BSE100 and three other markets: FTSE, Nikkei225 and AKM. Unlike other covariances, in normal periods the covariance between SSE and DJIA $\left(\sigma_{C D}\right)$ does not depend on the volatilities of returns in developed markets. It may reflect the low degree of integration of China with other markets due to restrictions on foreign trading in Chinese stock markets and thus indicate unexploited portfolio diversification benefits. This finding supports the view that emerging stock markets have low correlations with the global market e.g. Bekaert et al. (1997), Bekaert and Harvey (2003) and $\mathrm{Li}$ and Majerowska (2008). We find that the coefficient of $\sigma_{D}^{2}$ is positive, supporting the theoretical finding that the coefficient of $\Lambda_{m m}$ should be positive if the assets are substitutes. The significant constant terms in the regressions of $\sigma_{F D}$ and $\sigma_{R D}$ also reflect the existence of correlations among UK, US and Russian fundamental shocks. The insignificant constant terms of $\sigma_{N D}, \sigma_{C D}$ and $\sigma_{I D}$ are consistent with the observation of low correlation between the Asian and US fundamental shocks.

According to Panel B, the Asian financial crisis lowers the mean value of $\sigma_{C D}$, but does not significantly affect the mean value of other covariances. This evidence also suggests that the correlation between Chinese and US fundamental shocks fell or traders' sensitivity to asset returns changed during the Asian financial crisis. Unlike normal periods, $\sigma_{F D}$ becomes 
more related to the volatilities of Asian stock markets and their comovement with FTSE during the Asian financial crisis. Moreover, $\sigma_{N D}$ falls with covariances of FTSE with Asian stock markets (Nikkei225, SSE and BSE100), but rises with the volatility of AKM $\left(\sigma_{R}^{2}\right)$ and the covariance between Nikkei225 and BSE100 $\left(\sigma_{N I}\right)$. With regard to SSE, its covariance depends more on the volatility of developed markets and its own volatility during the Asian financial crisis. In addition, it rises with covariances of other crisis markets (Nikkei225 and $\mathrm{AKM}$ ) with BSE100, but falls with covariances of these crisis markets with SSE and $\sigma_{F N}$. Unlike $\sigma_{I D}$ in normal periods, in the crisis period it is affected by their own volatilities and the $\sigma_{R}^{2}$ and falls with covariances among Nikkei225, AKM and BSE100. While $\sigma_{R D}$ links to developed markets only in the normal period, it becomes more related to three Asian stock markets in our sample during the Asian financial crisis. This finding supports the results of Pinto and Ulatov (2010) that there was spillover of the East Asian crisis to Russia in November 1997, therefore Russia faced an economic crisis in August 1998 after almost complete privatization of its manufacturing and natural resource sectors and the surge in capital inflows in 1997.

Regarding the effect of the recent global financial crisis shown in Panel C, the crisis lowers only the mean value of $\sigma_{I D}$. This finding may stem from the lower correlation between Indian and US fundamental shocks or changes in traders' sensitivity to a set of asset returns during the global financial crisis. The result in Panel C shows that $\sigma_{D}^{2}$ raises covariances of FTSE, SSE and AKM with DJIA while an increase in $\sigma_{F}^{2}$ raises covariances of FTSE and BSE100 with DJIA. Considering $\sigma_{F D}$, it rises with covariances between developed and emerging markets i.e. $\sigma_{F I}$ and $\sigma_{N C}$ but falls with the covariance between emerging markets i.e. $\sigma_{C I}$. While $\sigma_{N D}$ does not depend on its own volatility in the normal period or the Asian financial crisis period, it does in the recent global financial crisis. Unlike $\sigma_{F D}, \sigma_{N D}$ rises with covariances between markets with the same development level i.e. $\sigma_{F N}$ and $\sigma_{C R}$, but falls with 
covariances between developed and emerging markets i.e. $\sigma_{F C}$ and $\sigma_{N R}$. While $\sigma_{C D}$ is not related to $\sigma_{N}^{2}$ in the normal period, it rises with $\sigma_{N}^{2}$ in both Asian and global financial crises. During the global financial crisis $\sigma_{C D}$ increases with the covariance between markets in different regions i.e. $\sigma_{F C}$; whereas, it decreases with covariances between markets in the same region i.e. $\sigma_{F R}$ and $\sigma_{N C}$. Regarding $\sigma_{I D}$, while it is insignificantly affected by $\sigma_{I}^{2}$ in normal periods, it significantly rises with $\sigma_{I}^{2}$ during both Asian and global financial crises. Unlike normal periods and the Asian financial crisis period, during the recent financial crisis $\sigma_{I D}$ also changes significantly with the covariance between FTSE and the other three markets: Nikkei225, SSE and AKM. As in the Asian financial crisis period, during the global financial crisis $\sigma_{R D}$ is significantly related to the covariances among Asian stock markets (Nikkei225, SSE, BSE100).

The sample includes periods of high global instability in different parts of the world as well as those of more "normal times". Despite this heterogeneity we have stable regressions across countries and time. The fit is generally very good. The adjusted $R^{2}$ of the model in Table 1 is much higher than that of models with only variance terms as explanatory variables (See Table 4-6 in Appendix 4). A likelihood ratio test rejects excluding the covariance terms. The Breusch-Godfrey serial correlation test and the Ramsey's RESET statistics in Table 1 also indicate that there is no evidence of autocorrelation or mis-specification problems while these problems exist in the models with only variance terms as explanatory variables (See Table 4-6 in Appendix 4). All variables in the system are stationary and so are residuals (See Table 2). That is, there are stable linear relationships between the second moment series. The Theil-inequality indexes are also close to zero and much lower than the indices of the model without dummy variables and those of models in which the asset covariance relates to variances only (See Appendix 4). 
Table 1: OLS regressions of equation (22)

\begin{tabular}{|c|c|c|c|c|c|c|c|c|c|c|}
\hline \multirow{2}{*}{$\begin{array}{l}\text { Independent Variables } \\
\text { Panel A }\end{array}$} & \multicolumn{2}{|l|}{$\sigma_{F D}$} & \multicolumn{2}{|l|}{$\sigma_{N D}$} & \multicolumn{2}{|l|}{$\sigma_{C D}$} & \multicolumn{2}{|l|}{$\sigma_{I D}$} & \multicolumn{2}{|l|}{$\sigma_{R D}$} \\
\hline & & & & & & & & & & \\
\hline$\sigma_{F}^{2}$ & 0.312 & ** & -0.253 & ** & 0.063 & & -0.169 & ** & -0.135 & \\
\hline$\sigma_{N}^{2}$ & -0.010 & & 0.020 & & -0.035 & & 0.013 & & 0.011 & \\
\hline$\sigma_{C}^{2}$ & -0.001 & & -0.001 & & -0.013 & & 0.002 & & 0.001 & \\
\hline$\sigma_{I}^{2}$ & -0.012 & & 0.025 & ** & -0.001 & & -0.001 & & 0.027 & \\
\hline$\sigma_{R}^{2}$ & -0.003 & & -0.004 & & 0.008 & & -0.005 & & 0.039 & ** \\
\hline$\sigma_{F N}$ & 0.049 & & 0.735 & $* *$ & 0.042 & & -0.044 & & 0.292 & \\
\hline$\sigma_{F C}$ & 0.003 & & -0.013 & & 0.357 & ** & 0.003 & & 0.044 & \\
\hline$\sigma_{F I}$ & 0.005 & & 0.037 & & -0.100 & & 0.365 & $* *$ & -0.091 & \\
\hline$\sigma_{F R}$ & 0.029 & & -0.004 & & 0.047 & & -0.055 & & 0.564 & ** \\
\hline$\sigma_{N C}$ & 0.016 & & 0.012 & & 0.091 & & 0.044 & & -0.043 & \\
\hline$\sigma_{N I}$ & 0.007 & & -0.063 & & 0.080 & & 0.144 & $* *$ & -0.076 & \\
\hline$\sigma_{N R}$ & 0.002 & & 0.054 & & 0.015 & & 0.022 & & 0.043 & \\
\hline$\sigma_{C I}$ & 0.009 & & 0.027 & & -0.004 & & 0.004 & & -0.039 & \\
\hline$\sigma_{C R}$ & 0.006 & & -0.006 & & 0.064 & & -0.002 & & 0.023 & \\
\hline$\sigma_{I R}$ & -0.008 & & 0.014 & & -0.049 & & 0.094 & ** & -0.068 & \\
\hline$\sigma_{D}^{2}$ & 0.293 & $* *$ & 0.214 & ** & -0.056 & & 0.157 & ** & 0.149 & * \\
\hline $\mathrm{C}$ & -0.331 & $* *$ & 0.122 & & 0.174 & & 0.321 & & -1.045 & * \\
\hline \multicolumn{11}{|l|}{ Panel B } \\
\hline$\sigma_{F}^{2} \times \mathrm{AFC}$ & -0.059 & & 0.266 & * & 0.300 & $* *$ & 0.285 & ** & 0.465 & \\
\hline$\sigma_{N}^{2} \times \mathrm{AFC}$ & -0.044 & & 0.009 & & 0.189 & ** & -0.108 & & -0.124 & \\
\hline$\sigma_{C}^{2} \times \mathrm{AFC}$ & 0.022 & ** & -0.001 & & -0.058 & ** & 0.019 & & 0.076 & \\
\hline$\sigma_{I}^{2} \times \mathrm{AFC}$ & 0.073 & ** & 0.037 & & -0.019 & & 0.153 & $* *$ & 0.179 & \\
\hline$\sigma_{R}^{2} \times \mathrm{AFC}$ & 0.001 & & 0.008 & * & 0.004 & & 0.010 & $* *$ & -0.038 & ** \\
\hline$\sigma_{F N} \times \mathrm{AFC}$ & -0.102 & & -0.472 & * & -0.981 & ** & 0.194 & & -0.025 & \\
\hline$\sigma_{F C} \times \mathrm{AFC}$ & -0.247 & $* *$ & -0.134 & * & 0.050 & & -0.115 & & -1.427 & ** \\
\hline$\sigma_{F I} \times \mathrm{AFC}$ & 0.093 & * & -0.231 & $* *$ & 0.147 & & 0.033 & & 0.033 & \\
\hline$\sigma_{F R} \times \mathrm{AFC}$ & -0.038 & & 0.041 & & -0.052 & & 0.013 & & -0.358 & ** \\
\hline$\sigma_{N C} \times \mathrm{AFC}$ & -0.010 & & -0.064 & & -0.151 & * & -0.002 & & 0.432 & ** \\
\hline$\sigma_{N I} \times \mathrm{AFC}$ & -0.015 & & 0.361 & ** & 0.333 & ** & -0.323 & ** & -0.334 & \\
\hline$\sigma_{N R} \times \mathrm{AFC}$ & -0.006 & & -0.033 & & 0.046 & & -0.094 & ** & 0.091 & \\
\hline$\sigma_{C I} \times \mathrm{AFC}$ & 0.035 & & 0.057 & & 0.305 & ** & -0.147 & ** & -0.159 & \\
\hline$\sigma_{C R} \times \mathrm{AFC}$ & 0.049 & ** & 0.000 & & -0.145 & * & 0.044 & & 0.557 & ** \\
\hline$\sigma_{I R} \times \mathrm{AFC}$ & -0.005 & & -0.059 & & -0.004 & & -0.144 & ** & 0.314 & ** \\
\hline$\sigma_{D}^{2} \times \mathrm{AFC}$ & 0.061 & & -0.202 & * & -0.141 & ** & 0.046 & & -0.058 & \\
\hline $\mathrm{AFC}$ & -0.551 & & -0.834 & & -2.948 & ** & -2.153 & & -1.374 & \\
\hline \multicolumn{11}{|l|}{ Panel C } \\
\hline$\sigma_{F}^{2} \times \mathrm{GFC}$ & -0.089 & * & -0.028 & & -0.128 & & 0.333 & ** & -0.141 & \\
\hline$\sigma_{N}^{2} \times \mathrm{GFC}$ & -0.015 & & -0.128 & ** & 0.092 & * & 0.008 & & -0.027 & \\
\hline$\sigma_{C}^{2} \times \mathrm{GFC}$ & -0.001 & & -0.025 & * & 0.002 & & 0.014 & & 0.002 & \\
\hline$\sigma_{I}^{2} \times \mathrm{GFC}$ & -0.009 & & -0.041 & & 0.060 & & 0.125 & $* *$ & -0.086 & ** \\
\hline$\sigma_{R}^{2} \times \mathrm{GFC}$ & 0.004 & & -0.002 & & 0.003 & & 0.006 & & -0.025 & \\
\hline$\sigma_{F N} \times \mathrm{GFC}$ & 0.086 & & 0.766 & ** & -0.195 & & 0.463 & * & -0.207 & \\
\hline$\sigma_{F C} \times \mathrm{GFC}$ & 0.039 & & -0.239 & * & 0.692 & ** & -0.305 & ** & -0.260 & \\
\hline$\sigma_{F I} \times \mathrm{GFC}$ & 0.138 & ** & 0.130 & & -0.037 & & 0.032 & & 0.271 & \\
\hline$\sigma_{F R} \times \mathrm{GFC}$ & -0.043 & & 0.039 & & -0.163 & * & 0.200 & ** & 0.181 & \\
\hline$\sigma_{N C} \times \mathrm{GFC}$ & 0.059 & * & -0.080 & & -0.265 & * & -0.094 & & 0.416 & ** \\
\hline$\sigma_{N I} \times \mathrm{GFC}$ & -0.058 & & 0.050 & & 0.032 & & -0.181 & & -0.279 & ** \\
\hline$\sigma_{N R} \times \mathrm{GFC}$ & -0.008 & & -0.185 & ** & -0.047 & & -0.395 & $* *$ & -0.093 & \\
\hline$\sigma_{C I} \times \mathrm{GFC}$ & -0.089 & ** & -0.020 & & -0.043 & & 0.124 & & -0.088 & \\
\hline$\sigma_{C R} \times \mathrm{GFC}$ & 0.012 & & 0.160 & $* *$ & -0.015 & & 0.029 & & 0.082 & \\
\hline$\sigma_{I R} \times \mathrm{GFC}$ & 0.020 & & -0.002 & & 0.008 & & 0.015 & & 0.265 & ** \\
\hline$\sigma_{D}^{2} \times \mathrm{GFC}$ & 0.116 & ** & -0.007 & & 0.361 & ** & -0.053 & & 0.267 & ** \\
\hline GFC & 0.019 & & -0.146 & & -0.950 & & -2.058 & ** & 0.415 & \\
\hline " Adjusted R-squared & 0.97 & & 0.89 & & 0.76 & & 0.88 & & 0.96 & \\
\hline LR stat (P-Value) & 153.62 & & $288.44(0.0$ & & $358.00(0$ & 00) & $283.92(0$ & & $533.47(0$. & \\
\hline Theil Inequality Coef. & 0.07 & & 0.14 & & 0.23 & & 0.15 & & 0.08 & \\
\hline AR (P-Value) & $0.86(0.66$ & & $1.39(0.12$ & & $0.95(0.5$ & & $0.75(0.7$ & & $1.28(0.1$ & \\
\hline Ramsey (P-Value) & $0.60(0.4$ & & $0.32(0.57$ & & $1.78(0.1$ & & $0.26(0.6$ & & $2.83(0.0$ & \\
\hline
\end{tabular}


Table 2: Descriptive statistics of estimated residuals

Dependent Variables

\begin{tabular}{lccccc}
\hline \hline & $\sigma_{F D}$ & $\sigma_{N D}$ & $\sigma_{C D}$ & $\sigma_{I D}$ & $\sigma_{R D}$ \\
\hline \hline Mean & $1.34 \times 10^{-11}$ & $-1.34 \times 10^{-11}$ & $-8.93 \times 10^{-12}$ & $8.70 \times 10^{-17}$ & $8.93 \times 10^{-12}$ \\
Standard Deviation & 1.059 & 1.817 & 2.403 & 2.190 & 2.891 \\
ADF-stat & -15.074 & -13.437 & -12.718 & -14.632 & -16.916 \\
ADF P(Value) & 0.000 & 0.000 & 0.000 & 0.000 & 0.000 \\
\hline \hline
\end{tabular}

ADF critical values $\quad 1 \%$ level: $-2.575 \quad 5 \%$ level: $-1.942 \quad 10 \%$ level: -1.616

To sum up, we find the covariances between two market returns can be affected by not only their own volatility but also volatilities and covariances of the other markets. The significance of coefficients in Panel B and C indicates that how they are related in normal and crisis periods are different. While the comovement between the UK market and the US market is only affected by their own volatilities during the normal periods, it is also affected by volatilities and comovement of emerging markets during the crisis periods. For the emerging markets, during normal periods the covariance between an emerging market and the US market depends on not only the volatility of the US market but also the volatility of the UK market or the covariance between its own market and the UK market, but during the financial crises it relates more to covariances of its own market and the Japanese market with other emerging markets. These results imply changes in investors' sensitivity to asset returns and how random shocks are correlated during crises. Compared to other frameworks in which covariances are explained by variances of market returns only, our framework has higher explanatory power and does not have mis-specification problems. These results imply the validity of our moment restrictions.

\section{Conclusions}

Existing asset pricing theories focus on representative investor behavior to derive the first moments or bounds of asset prices by appealing to no arbitrage and efficient pricing considerations. At the same time these restrictions are often empirically rejected. This has led to the development of quite highly structured theories to explain anomalies. Here, we have 
taken a theory-free framework with the only assumption that equilibrium asset returns reflect the interaction between intertemporal traders and short term flow and noise traders.

Our main result is that so long as the short term traders react to asset returns in more than one market, there is a set of linear restrictions on the covariance matrix of the equilibrium asset returns. These restrictions are testable just from asset returns data. The restrictions are robust in that they are independent of the investment decision rules used by the intertemporal traders. We also find a lower bound of correlation between two asset returns.

We have taken a two period horizon and a single round of maturity trading. One interesting extension would be to embed this in an overlapping generations model where each generation lives two periods. Then our intertemporal traders correspond to the old and the flow traders to the young - that is, their net supplies depend on not only previous prices but also current prices. The flow trader demands at $t+1$ would still depend on expected asset returns (and hence on asset prices at $t+1$ ) and their expectations of the maturity prices that they will face at $t+2\left(E_{t+1} p_{t+2}\right)$ and on the covariance matrix of asset returns. The approach to deriving second moment restrictions at any particular period would then still hold.

We have applied the results to aggregate stock returns for quite different markets for a sample that includes various abnormal periods. With stationary monthly variances and covariances of stock returns, overall we find that it has quite strong empirical validation. In general there are links between the second moments between asset returns that appear to be quite robust over time and space. In other words, changes in volatility and covariances of asset returns in some other markets can affect the covariance between asset returns in two particular markets. This helps to explain the evidence of increasing comovement between stock returns in different countries and continents both in normal periods and during the 1997 Asian financial crisis and the 2008 global financial crisis in which there have been high volatilities in stock markets of the crisis countries. In general, the empirical evidence shows 
that the linkages between emerging and developed markets are greater during crisis periods than in normal periods. During normal periods the comovement between two markets is mainly affected by their own volatilities and co-movements between those two markets with the other markets, but during the crises it is also affected by volatilities and comovements of the other markets.

The setting can also be applied to any asset markets such as derivative markets, especially futures markets in which intertemporal traders are closing out positions close to maturity. It can also be applied to commodity markets in which we have recently found co-movement among prices of oil, bio-fuel commodity, and precious metals. There is also recent evidence that increasing integration of asset markets influences the covariance and variance structure between markets. For example, until recently commodities and other financial assets had low correlations and a small volume of cross market trading (Erb and Harvey, 2006) but there was a strong rise in comovement across different commodity prices in 2007-2008. This may have been driven by a large influx of speculative investment funds from institutional investors following the innovation of commodity index futures (Balkombe, 2010; Hernandez and Torero, 2010; Tang and Xiong, 2010). In particular, Gilbert (2010) empirically finds that commodity prices have not always reflected market fundamentals, but there may be effects of speculation. In terms of our theory this would be modeled as the introduction of a new wave of flow traders into commodities.

\section{Appendix}

\section{A1. The relationship between asset returns}

Let $A^{-1}=\left[\begin{array}{ll}\alpha_{11} & \alpha_{1 m} \\ \alpha_{m 1}^{T} & \alpha_{m m}\end{array}\right]$ where $\alpha_{11}$ is $(m-1) \times(m-1) ; \alpha_{1 m}$ and $\alpha_{m 1}$ are $(m-1) \times 1$ vectors and $\alpha_{m m}$ is scalar. Partition the markets into the first $m-1$ and the last so (6) becomes

$$
\left[\begin{array}{c}
\left.r_{t+1}\right]_{-m} \\
r_{m t+1}
\end{array}\right]=A^{-1}\left(\left[\begin{array}{c}
X_{-m} \\
X_{m t+1}
\end{array}\right]-\left[\begin{array}{c}
{\left[\varepsilon_{t+1}\right]_{-m}} \\
\varepsilon_{m t+1}
\end{array}\right]\right)-\left[\begin{array}{c}
\iota_{-m} \\
1
\end{array}\right]+\left[\begin{array}{c}
\left.\eta_{t+1}\right]_{-m} \\
\eta_{m t+1}
\end{array}\right]
$$

where $\left[\varepsilon_{t+1}\right]_{-m}^{T}=\left(\varepsilon_{1 t+1}, \varepsilon_{2 t+1}, \ldots, \varepsilon_{(m-1), t+1}\right), X_{-m}^{T}=\left(X_{1 t+1}, X_{2 t+1}, \ldots, X_{(m-1), t+1}\right)$ and $l_{-m}$ is the $(m-1) \times 1$ 
unit vector. Note that (23) holds with probability one in $\varepsilon_{t+1}:$ this generates the restrictions we find. From the first $m-1$ equations of (23),

$$
\left[\varepsilon_{t+1}\right]_{-m}=X_{-m}-A_{11} l_{-m}-A_{1 m}-A_{11}\left[r_{t+1}\right]_{-m}-A_{1 m} r_{m t+1}+A_{11}\left[\eta_{t+1}\right]_{-m}+A_{1 m} \eta_{m t+1}
$$

Substituting (24) into the last equation of (23)

$$
r_{m t+1}=\alpha_{m 1}^{T} X_{-m}+\alpha_{m m} X_{m t+1}-\alpha_{m 1}^{T}\left[\varepsilon_{t+1}\right]_{-m}-\alpha_{m m} \varepsilon_{m t+1}-1+\eta_{m t+1}
$$

yields

$$
r_{m t+1}=\frac{\alpha_{m m} X_{m t+1}-1-\alpha_{m m} \varepsilon_{m t+1}+\eta_{m t+1}}{\left(1-\alpha_{m 1}^{T} A_{1 m}\right)}+\frac{\alpha_{m 1}^{T}\left(A_{1 m}-A_{1 m} \eta_{m t+1}\right)}{\left(1-\alpha_{m 1}^{T} A_{1 m}\right)}+\frac{\alpha_{m 1}^{T}\left[A_{11} l_{-m}+A_{11}\left[r_{t+1}\right]_{-m}-A_{11}\left[\eta_{t+1}\right]_{-m}\right]}{\left(1-\alpha_{m 1}^{T} A_{1 m}\right)}
$$

Computing the elements of $A^{-1}$,

$$
\alpha_{11}=A_{11}^{-1}-\frac{1}{A_{m 1}^{T} A_{11}^{-1} A_{1 m}-a_{m m}} A_{11}^{-1} A_{1 m} A_{m 1}^{T} A_{11}^{-1}, \alpha_{m 1}^{T}=\frac{A_{m 1}^{T} A_{11}^{-1}}{A_{m 1}^{T} A_{11}^{-1} A_{1 m}-a_{m m}}, \alpha_{m m}=-\frac{1}{A_{m 1}^{T} A_{11}^{-1} A_{1 m}-a_{m m}}
$$

so that finally we have the equation

$$
r_{m t+1}=\frac{X_{m t+1}}{a_{m m}}-\left(\frac{A_{m 1}^{T}}{a_{m m}} l_{-m}+1\right)-\frac{A_{m 1}^{T}}{a_{m m}}\left(\left[r_{t+1}\right]_{-m}-\left[\eta_{t+1}\right]_{-m}\right)-\frac{\varepsilon_{m t+1}}{a_{m m}}+\eta_{m t+1}
$$

\section{A2. The second moments of returns}

The variance-covariance matrix of returns is

$$
\operatorname{var}\left(r_{t+1}\right)=\Lambda=\operatorname{var}\left(A^{-1}\left(\varepsilon_{t+1}-A \eta_{t+1}\right)\right)=A^{-T} \operatorname{var}\left(\varepsilon_{t+1}-A \eta_{t+1}\right) A^{-1}=A^{-T} \Sigma A^{-1}
$$

where

$$
\Sigma=\operatorname{var}\left(\varepsilon_{t+1}-A \eta_{t+1}\right)=\operatorname{var}(\varepsilon)+\operatorname{var}(A \eta)=\Gamma+A^{T} \operatorname{var}(\eta) A
$$

The second term of $\Sigma$ is

$$
A^{T} \operatorname{var}(\eta) A=\left[\begin{array}{cccc}
\sum_{i=1}^{m} \operatorname{var}\left(\eta_{i}\right) a_{i 1}^{2} & \sum_{i=1}^{m} \operatorname{var}\left(\eta_{i}\right) a_{i 2} a_{i 1} & \cdots & \sum_{i=1}^{m} \operatorname{var}\left(\eta_{i}\right) a_{i m} a_{i 1} \\
\sum_{i=1}^{m} \operatorname{var}\left(\eta_{i}\right) a_{i 2} a_{i 1} & \ddots & & \vdots \\
\vdots & & \ddots & \vdots \\
\sum_{i=1}^{m} \operatorname{var}\left(\eta_{i}\right) a_{i m} a_{i 1} & \cdots & \ldots & \sum_{i=1}^{m} \operatorname{var}\left(\eta_{i}\right) a_{i m}^{2}
\end{array}\right]
$$

so

$$
\Sigma=\left[\begin{array}{cccc}
\gamma_{11}+\sum_{i=1}^{m} a_{i 1}^{2} \operatorname{var}\left(\eta_{i}\right) & \gamma_{12}+\sum_{i=1}^{m} a_{i 1} a_{i 2} \operatorname{var}\left(\eta_{i}\right) & \cdots & \gamma_{1 m}+\sum_{i=1}^{m} a_{i 1} a_{i m} \operatorname{var}\left(\eta_{i}\right) \\
\gamma_{12}+\sum_{i=1}^{m} a_{i 1} a_{i 2} \operatorname{var}\left(\eta_{i}\right) & \gamma_{22}+\sum_{i=1}^{m} a_{i 2}^{2} \operatorname{var}\left(\eta_{i}\right) & & \vdots \\
\vdots & \ldots & \ddots & \vdots \\
\gamma_{1 m}+\sum_{i=1}^{m} a_{i 1} a_{i m} \operatorname{var}\left(\eta_{i}\right) & \cdots & \gamma_{m m}+\sum_{i=1}^{m} a_{i m}^{2} \operatorname{var}\left(\eta_{i}\right)
\end{array}\right]
$$

From (26), the variance-covariance matrix of $m$ asset returns: 
from which

$$
\left[\begin{array}{cc}
\Lambda_{11} & \Lambda_{1 m} \\
\Lambda_{1 m}^{T} & \Lambda_{m m}
\end{array}\right]=\left[\begin{array}{cc}
\alpha_{11}^{T} & \alpha_{m 1} \\
\alpha_{1 m}^{T} & \alpha_{m m}
\end{array}\right]\left[\begin{array}{cc}
\Sigma_{11} & \Sigma_{1 m} \\
\Sigma_{1 m}^{T} & \Sigma_{m m}
\end{array}\right]\left[\begin{array}{cc}
\alpha_{11} & \alpha_{1 m} \\
\alpha_{m 1}^{T} & \alpha_{m m}
\end{array}\right]
$$

$$
\begin{aligned}
\Lambda_{11} & =\alpha_{11}^{T} \Sigma_{11} \alpha_{11}+\alpha_{m 1} \Sigma_{1 m}^{T} \alpha_{11}+\alpha_{11}^{T} \Sigma_{1 m} \alpha_{m 1}^{T}+\alpha_{m 1} \Sigma_{m m} \alpha_{m 1}^{T} \\
\Lambda_{m m} & =\alpha_{1 m}^{T} \Sigma_{11} \alpha_{1 m}+\alpha_{m m} \Sigma_{1 m}^{T} \alpha_{1 m}+\alpha_{1 m}^{T} \Sigma_{1 m} \alpha_{m m}+\alpha_{m m} \Sigma_{m m} \alpha_{m m} \\
\Lambda_{1 m} & =\alpha_{11}^{T} \Sigma_{11} \alpha_{1 m}+\alpha_{m 1} \Sigma_{1 m}^{T} \alpha_{1 m}+\alpha_{11}^{T} \Sigma_{1 m} \alpha_{m m}+\alpha_{m 1} \Sigma_{m m} \alpha_{m m}
\end{aligned}
$$

From the first equation of (27),

$$
\begin{aligned}
\Sigma_{11} & =\alpha_{11}^{-T} \Lambda_{11} \alpha_{11}^{-1}-\alpha_{11}^{-T} \alpha_{m 1} \Sigma_{1 m}^{T} \alpha_{11} \alpha_{11}^{-1}-\alpha_{11}^{-T} \alpha_{11}^{T} \Sigma_{1 m} \alpha_{m 1}^{T} \alpha_{11}^{-1}-\alpha_{11}^{-T} \alpha_{m 1} \Sigma_{m m} \alpha_{m 1}^{T} \alpha_{11}^{-1} \\
& =\alpha_{11}^{-T} \Lambda_{11} \alpha_{11}^{-1}-\alpha_{11}^{-T} \alpha_{m 1} \Sigma_{1 m}^{T}-\Sigma_{1 m} \alpha_{m 1}^{T} \alpha_{11}^{-1}-\alpha_{11}^{-T} \alpha_{m 1} \Sigma_{m m} \alpha_{m 1}^{T} \alpha_{11}^{-1}
\end{aligned}
$$

Substitute this in the second equation of (27) and recall that $\Sigma_{m m}$ is a scalar

$$
\begin{aligned}
\Lambda_{m m}= & \alpha_{1 m}^{T} \alpha_{11}^{-T} \Lambda_{11} \alpha_{11}^{-1} \alpha_{1 m}-\alpha_{1 m}^{T} \alpha_{11}^{-T} \alpha_{m 1} \Sigma_{1 m}^{T} \alpha_{1 m}-\alpha_{1 m}^{T} \Sigma_{1 m} \alpha_{m 1}^{T} \alpha_{11}^{-1} \alpha_{1 m}-\alpha_{1 m}^{T} \alpha_{11}^{-T} \alpha_{m 1} \Sigma_{m m} \alpha_{m 1}^{T} \alpha_{11}^{-1} \alpha_{1 m} \\
& +\alpha_{m m} \Sigma_{1 m}^{T} \alpha_{1 m}+\alpha_{1 m}^{T} \Sigma_{1 m} \alpha_{m m}+\alpha_{m m} \Sigma_{m m} \alpha_{m m} \\
= & \alpha_{1 m}^{T} \alpha_{11}^{-T} \Lambda_{11} \alpha_{11}^{-1} \alpha_{1 m}-\alpha_{1 m}^{T} \alpha_{11}^{-T} \alpha_{m 1} \Sigma_{1 m}^{T} \alpha_{1 m}-\alpha_{1 m}^{T} \Sigma_{1 m} \alpha_{m 1}^{T} \alpha_{11}^{-1} \alpha_{1 m}+\alpha_{m m} \Sigma_{1 m}^{T} \alpha_{1 m}+\alpha_{1 m}^{T} \Sigma_{1 m} \alpha_{m m} \\
& +\left(\alpha_{m m} \alpha_{m m}-\alpha_{1 m}^{T} \alpha_{11}^{-T} \alpha_{m 1} \alpha_{m 1}^{T} \alpha_{11}^{-1} \alpha_{1 m}\right) \Sigma_{m m} \\
\Sigma_{m m}= & \frac{\left[\Lambda_{m m}-\alpha_{1 m}^{T} \alpha_{11}^{-T} \Lambda_{11} \alpha_{11}^{-1} \alpha_{1 m}+\alpha_{1 m}^{T}\left(\alpha_{11}^{-T} \alpha_{m 1} \Sigma_{1 m}^{T}+\Sigma_{1 m} \alpha_{m 1}^{T} \alpha_{11}^{-1}\right) \alpha_{1 m}-\alpha_{m m} \Sigma_{1 m}^{T} \alpha_{1 m}-\alpha_{1 m}^{T} \Sigma_{1 m} \alpha_{m m}\right]}{\left(\alpha_{m m} \alpha_{m m}-\alpha_{1 m}^{T} \alpha_{11}^{-T} \alpha_{m 1} \alpha_{m 1}^{T} \alpha_{11}^{-1} \alpha_{1 m}\right)}
\end{aligned}
$$

where $\alpha_{m m} \alpha_{m m}-\alpha_{1 m}^{T} \alpha_{11}^{-T} \alpha_{m 1} \alpha_{m 1}^{T} \alpha_{11}^{-1} \alpha_{1 m}$ is a scalar. Substitute $\Sigma_{11}$ and $\Sigma_{m m}$ into the last equation of (27)

$$
\begin{aligned}
\Lambda_{1 m}= & \alpha_{11}^{T}\left(\alpha_{11}^{-T} \Lambda_{11} \alpha_{11}^{-1}-\alpha_{11}^{-T} \alpha_{m 1} \Sigma_{1 m}^{T}-\Sigma_{1 m} \alpha_{m 1}^{T} \alpha_{11}^{-1}-\alpha_{11}^{-T} \alpha_{m 1} \Sigma_{m m} \alpha_{m 1}^{T} \alpha_{11}^{-1}\right) \alpha_{1 m} \\
& +\alpha_{m 1} \Sigma_{1 m}^{T} \alpha_{1 m}+\alpha_{11}^{T} \Sigma_{1 m} \alpha_{m m}+\alpha_{m 1} \Sigma_{m m} \alpha_{m m} \\
= & \Lambda_{11} \alpha_{11}^{-1} \alpha_{1 m}-\alpha_{m 1} \Sigma_{1 m}^{T} \alpha_{1 m}-\alpha_{11}^{T} \Sigma_{1 m} \alpha_{m 1}^{T} \alpha_{11}^{-1} \alpha_{1 m}+\alpha_{m 1} \Sigma_{1 m}^{T} \alpha_{1 m}+\alpha_{11}^{T} \Sigma_{1 m} \alpha_{m m} \\
& +\frac{\alpha_{m 1}\left(\alpha_{m m}-\alpha_{m 1}^{T} \alpha_{11}^{-1} \alpha_{1 m}\right)}{\left(\alpha_{m m}^{2}-\alpha_{1 m}^{T} \alpha_{11}^{-T} \alpha_{m 1} \alpha_{m 1}^{T} \alpha_{11}^{-1} \alpha_{1 m}\right)} \\
& {\left[\Lambda_{m m}-\alpha_{1 m}^{T} \alpha_{11}^{-T} \Lambda_{11} \alpha_{11}^{-1} \alpha_{1 m}+\alpha_{1 m}^{T}\left(\alpha_{11}^{-T} \alpha_{m 1} \Sigma_{1 m}^{T}+\Sigma_{1 m} \alpha_{m 1}^{T} \alpha_{11}^{-1}\right) \alpha_{1 m}-\alpha_{m m}\left(\Sigma_{1 m}^{T} \alpha_{1 m}+\alpha_{1 m}^{T} \Sigma_{1 m}\right)\right] } \\
= & \Lambda_{11} \alpha_{11}^{-1} \alpha_{1 m}-\alpha_{11}^{T} \Sigma_{1 m} \alpha_{m 1}^{T} \alpha_{11}^{-1} \alpha_{1 m}+\alpha_{11}^{T} \Sigma_{1 m} \alpha_{m m}+\frac{\alpha_{m 1}\left(\alpha_{m m}-\alpha_{m 1}^{T} \alpha_{11}^{-1} \alpha_{1 m}\right)}{\left(\alpha_{m m}^{2}-\alpha_{1 m}^{T} \alpha_{11}^{-T} \alpha_{m 1} \alpha_{m 1}^{T} \alpha_{11}^{-1} \alpha_{1 m}\right)} \\
& {\left[\Lambda_{m m}-\alpha_{1 m}^{T} \alpha_{11}^{-T} \Lambda_{11} \alpha_{11}^{-1} \alpha_{1 m}+\alpha_{1 m}^{T} \Sigma_{1 m}\left(\alpha_{1 m}^{T} \alpha_{11}^{-T} \alpha_{m 1}+\alpha_{m 1}^{T} \alpha_{11}^{-1} \alpha_{1 m}\right)-2 \alpha_{m m} \alpha_{1 m}^{T} \Sigma_{1 m}\right] }
\end{aligned}
$$

Note $\Sigma_{1 m}^{T} \alpha_{1 m}=\alpha_{1 m}^{T} \Sigma_{1 m}, \alpha_{1 m}^{T} \alpha_{11}^{-T} \alpha_{m 1}=\alpha_{m 1}^{T} \alpha_{11}^{-1} \alpha_{1 m}$ and these terms are scalars.

$$
\begin{aligned}
\Lambda_{1 m}= & \Lambda_{11} \alpha_{11}^{-1} \alpha_{1 m}+\frac{\alpha_{m 1}}{\left(\alpha_{m m}+\alpha_{m 1}^{T} \alpha_{11}^{-1} \alpha_{1 m}\right)}\left(\Lambda_{m m}-\alpha_{1 m}^{T} \alpha_{11}^{-T} \Lambda_{11} \alpha_{11}^{-1} \alpha_{1 m}\right) \\
& +\left(\alpha_{m m}-\alpha_{m 1}^{T} \alpha_{11}^{-1} \alpha_{1 m}\right)\left(\alpha_{11}^{T} \Sigma_{1 m}-\frac{\alpha_{m 1}}{\left(\alpha_{m m}+\alpha_{m 1}^{T} \alpha_{11}^{-1} \alpha_{1 m}\right)}\left(\Sigma_{1 m}^{T} \alpha_{1 m}+\alpha_{1 m}^{T} \Sigma_{1 m}\right)\right) \\
= & \left.\left(I-\frac{a_{m 1} \alpha_{1 m}^{T} \alpha_{11}^{-T}}{\left(\alpha_{m m}+\alpha_{m 1}^{T} \alpha_{11}^{-1} \alpha_{1 m}\right)}\right) \Lambda_{11} \alpha_{11}^{-1} \alpha_{1 m}+\frac{\alpha_{m 1}}{\left(\alpha_{m m}+\alpha_{m 1}^{T} \alpha_{11}^{-1} \alpha_{1 m}\right)} \Lambda_{m m}\right) \\
& +\left(\alpha_{11}^{T}-\frac{2 \alpha_{m 1} \alpha_{1 m}^{T}}{\left(\alpha_{m m}+\alpha_{m 1}^{T} \alpha_{11}^{-1} \alpha_{1 m}\right)}\right) \Sigma_{1 m}\left(\alpha_{m m}-\alpha_{m 1}^{T} \alpha_{11}^{-1} \alpha_{1 m}\right)
\end{aligned}
$$




\section{A3. Stationarity Test on Variables}

ADF t-statistics of the second moments are shown in Table 2. For example, the ADF t-statistic of $\operatorname{Var}(F)$ is -11.589 and the $A D F$ t-statistic of $\operatorname{Cov}(F, N)$ is -12.074 . The result shows that the null hypothesis of unit root can be rejected for all second moments i.e. all dependent and independent variables in regressions are stationary.

Table 3: Augmented Dickey-Fuller (ADF)Test on Variances and Covariances of Index Returns

\begin{tabular}{|c|cccccc|}
\hline Stock Markets & F & N & C & I & R & D \\
\hline F & -11.589 & & & & & \\
N & -12.074 & -12.266 & & & & \\
C & -17.607 & -13.559 & -5.061 & & & \\
I & -13.868 & -14.641 & -14.549 & -14.647 & & \\
R & -12.865 & -11.537 & -18.203 & -14.223 & -4.405 & \\
D & -11.456 & -12.869 & -17.429 & -4.678 & -13.4 & -10.851 \\
\hline
\end{tabular}

\section{A4. Estimations of equation (22) without dummy variables and alternative models}

Table 4: OLS regression of the moment restriction implied by CAPM

\begin{tabular}{|c|c|c|c|c|c|}
\hline & \multicolumn{5}{|c|}{ Dependent Variables } \\
\hline Independent Variable & $\sigma_{F D}$ & $\sigma_{N D}$ & $\sigma_{C D}$ & $\sigma_{I D}$ & $\sigma_{R D}$ \\
\hline$\sigma_{\bar{D}}^{2}$ & 0.61 & 0.36 & 0.09 & 0.43 & 0.97 \\
\hline $\mathrm{C}$ & -0.21 & 0.57 & -0.04 & 0.32 & -1.53 \\
\hline Adjusted R-squared & 0.88 & 0.36 & 0.02 & 0.41 & 0.36 \\
\hline Mean of Residuals & $-4.66 \times 10^{-17}$ & $1.83 \times 10^{-15}$ & $2.78 \times 10^{-16}$ & $-2.10 \times 10^{-15}$ & $1.83 \times 10^{-15}$ \\
\hline Theil Inequality Coef. & 0.15 & 0.43 & 0.83 & 0.41 & 0.47 \\
\hline AR (F-stat) & $1.10(0.33)$ & $8.39(0.00)$ & $2.88(0.06)$ & $8.99(0.00)$ & $0.25(0.77)$ \\
\hline Ramsey (F-stat) & $4.50(0.03)$ & $0.82(0.37)$ & $31.46(0.00)$ & $3.21(0.07)$ & $20.44(0.00)$ \\
\hline
\end{tabular}

Note: ** for 0.05 significance level and * for 0.1 significance level

Table 5: OLS regression with variances of the $\mathrm{i}^{\text {th }}$ market and US markets

Dependent Variables

\begin{tabular}{|c|c|c|c|c|c|c|c|c|}
\hline Independent Variable & $\sigma_{F D}$ & & $\sigma_{N D}$ & & $\sigma_{C D}$ & $\sigma_{I D}$ & & $\sigma_{R D}$ \\
\hline$\sigma_{i}^{2}$ & 0.32 & ** & 0.20 & $* *$ & -0.02 & 0.12 & ** & 0.69 \\
\hline$\sigma_{D}^{2}$ & 0.35 & ** & 0.22 & $* *$ & 0.08 & 0.36 & ** & 0.05 \\
\hline $\mathrm{C}$ & -0.73 & ** & -0.72 & * & 0.39 & -1.26 & & -2.10 \\
\hline Adjusted R-squared & 0.95 & & 0.67 & & 0.05 & 0.57 & & 0.59 \\
\hline Mean of Residuals & $1.93 \times 10$ & & $4.93 \times 10^{-1}$ & & $4.51 \times 10^{-16}$ & $2.60 \times 10$ & & $1.36 \times 10^{-15}$ \\
\hline Theil Inequality Coef. & 0.10 & & 0.28 & & 0.77 & 0.33 & & 0.34 \\
\hline AR (F-stat) & $5.77(0.0$ & & $1.89(0.15$ & & $2.96(0.05)$ & $5.41(0.0$ & & $0.38(0.69)$ \\
\hline Ramsey (F-stat) & $2.75(0.1$ & & $2.38(0.12$ & & $8.91(0.00)$ & $28.73(0.0$ & & $11.35(0.00)$ \\
\hline
\end{tabular}

Note: $* *$ for 0.05 significance level and $*$ for 0.1 significance level 
Table 6: OLS regressions without covariance terms

Dependent Variables

\begin{tabular}{|c|c|c|c|c|c|c|c|c|c|}
\hline Independent Variables & \multicolumn{2}{|c|}{$\sigma_{F D}$} & \multicolumn{2}{|l|}{$\sigma_{N D}$} & $\sigma_{C D}$ & \multicolumn{2}{|l|}{$\sigma_{I D}$} & \multicolumn{2}{|l|}{$\sigma_{R D}$} \\
\hline$\sigma_{F}^{2}$ & 0.321 & ** & 0.081 & & -0.030 & 0.212 & ** & 0.432 & * \\
\hline$\sigma_{N}^{2}$ & 0.014 & & 0.184 & ** & -0.009 & 0.078 & ** & 0.154 & \\
\hline$\sigma_{C}^{2}$ & 0.001 & & 0.001 & & -0.017 & 0.001 & & 0.013 & \\
\hline$\sigma_{I}^{2}$ & -0.001 & & 0.001 & & 0.001 & 0.005 & ** & 0.043 & ** \\
\hline$\sigma_{R}^{2}$ & -0.005 & & 0.022 & & -0.024 & 0.084 & $* *$ & 0.082 & \\
\hline$\sigma_{D}^{2}$ & 0.351 & ** & 0.147 & & 0.128 & 0.121 & & 0.201 & \\
\hline $\mathrm{C}$ & -0.755 & ** & -1.094 & ** & 0.833 & -1.757 & ** & -5.214 & \\
\hline Adjusted R-squared & 0.95 & & 0.68 & & 0.05 & 0.65 & & 0.68 & \\
\hline Mean of Residuals & $-1.79 x$ & $0^{-11}$ & $4.91 \times 10^{-1}$ & & $-2.68 \times 10^{-11}$ & $-1.79 \times 10$ & & $8.04 \times 10^{-}$ & \\
\hline Theil Inequality Coef. & 0.10 & & 0.27 & & 0.74 & 0.29 & & 0.29 & \\
\hline AR (P-Value) & $1.82(0$ & 01) & $1.19(0.25$ & & $1.22(0.23)$ & $1.59(0.0$ & & $0.98(0.5$ & \\
\hline Ramsey (P-Value) & $2.88(0$ & 09) & $4.65(0.03$ & & $2.12(0.15)$ & $30.95(0.0$ & D) & $94.89(0.0$ & D) \\
\hline
\end{tabular}

Note: ** for 0.05 significance level and * for 0.1 significance level

Table 7: OLS regression of equation (22) without dummy variables

Dependent Variables

\begin{tabular}{|c|c|c|c|c|c|c|c|c|c|c|}
\hline Independent Variables & \multicolumn{2}{|l|}{$\sigma_{F D}$} & \multicolumn{2}{|l|}{$\sigma_{N D}$} & \multicolumn{2}{|l|}{$\sigma_{C D}$} & \multicolumn{2}{|l|}{$\sigma_{I D}$} & \multicolumn{2}{|l|}{$\sigma_{R D}$} \\
\hline 梅 ${ }_{F}^{2}$ & 0.230 & ** & -0.212 & ** & "-0.031 & & -0.116 & & -0.258 & ** \\
\hline$\sigma_{N}^{2}$ & -0.004 & & -0.006 & & 0.012 & & 0.023 & & -0.015 & \\
\hline$\sigma_{C}^{2}$ & -0.001 & & -0.002 & & -0.013 & & 0.000 & & 0.002 & \\
\hline$\sigma_{I}^{2}$ & -0.014 & ** & 0.013 & & 0.010 & & 0.041 & * & -0.004 & \\
\hline$\sigma_{R}^{2}$ & -0.004 & ** & -0.003 & ** & 0.004 & ** & -0.001 & & 0.008 & \\
\hline$\sigma_{F N}$ & 0.060 & & 0.807 & ** & 0.018 & & 0.061 & & 0.473 & ** \\
\hline$\sigma_{F C}$ & 0.006 & & -0.003 & & 0.531 & $* *$ & -0.009 & & -0.019 & \\
\hline$\sigma_{F I}$ & 0.043 & & -0.040 & & -0.009 & & 0.379 & ** & -0.204 & * \\
\hline$\sigma_{F R}$ & 0.049 & ** & 0.074 & ** & 0.098 & ** & 0.103 & * & 0.694 & ** \\
\hline$\sigma_{N C}$ & 0.027 & & 0.030 & & 0.067 & & 0.057 & & 0.021 & \\
\hline$\sigma_{N I}$ & 0.013 & & 0.036 & & -0.045 & & 0.051 & & 0.015 & \\
\hline$\sigma_{N R}$ & -0.030 & ** & -0.032 & & -0.048 & * & -0.036 & & -0.170 & * \\
\hline$\sigma_{C I}$ & 0.004 & & 0.016 & & 0.046 & & -0.013 & & -0.124 & ** \\
\hline$\sigma_{C R}$ & 0.012 & * & 0.009 & & 0.072 & & 0.007 & & 0.086 & \\
\hline$\sigma_{I R}$ & 0.013 & & -0.005 & & -0.083 & ** & 0.014 & & 0.203 & ** \\
\hline$\sigma_{D}^{2}$ & 0.380 & ** & 0.199 & ** & 0.087 & & 0.197 & ** & 0.319 & ** \\
\hline $\mathrm{C}$ & -0.446 & ** & 0.167 & & -0.224 & & -0.512 & & -0.825 & * \\
\hline $\begin{array}{l}\text { Adjusted R-squared } \\
\text { LR stat (P-Value) }\end{array}$ & $\begin{array}{r}0.96 \\
69.69(0 .\end{array}$ & & $\begin{array}{c}0.87 \\
207.72(0 .\end{array}$ & & $\begin{array}{l}0.65 \\
235.7\end{array}$ & & $\begin{array}{c}0.81 \\
144.54(0 .\end{array}$ & $.00)$ & $\begin{array}{c}0.92 \\
333.62\end{array}$ & \\
\hline Mean of Residuals & $4.46 \times 10$ & & $-4.46 \times 10^{-}$ & & $-8.93 \times 10$ & & $-6.25 \times 10^{-}$ & & $-2.68 \times 10$ & \\
\hline Theil Inequality Coef. & 0.08 & & 0.16 & & 0.31 & & 0.20 & & 0.13 & \\
\hline AR (P-Value) & $1.31(0.1$ & & $1.51(0.0$ & & $0.49(0.9$ & & $0.95(0.53$ & & $1.10(0.3$ & \\
\hline Ramsey (P-Value) & $5.07(0.0$ & & $0.05(0.8$ & & $8.23(0.0$ & & $1.44(0.23$ & & 43.83 & \\
\hline
\end{tabular}

Note: ** for 0.05 significance level and * for 0.1 significance level; For Likelihood Ratio (LR) test, $\mathrm{H}_{0}: \sigma_{i D}=\mathrm{f}\left(\sigma_{F}^{2}, \sigma_{N}^{2}\right.$, $\left.\sigma_{C}^{2}, \sigma_{I}^{2}, \sigma_{R}^{2}, \sigma_{D}^{2}\right)$

\section{References:}

Balkombe, K. (2010) The nature and determinants of volatility in agricultural prices: an empirical 
study from 1962-2008. Commodity Market Review 2009-2010, FAO, 1-24

Beirne, J., Caporale, G.M., Schulze-Ghattas, M. and Spagnolo, N. (2009) Volatility spillovers and contagion from mature to emerging stock markets. European Central Bank Working Paper Series, no. 1113

Bekaert, G., Erb, C., Harvey, C. and Viskanta, T. (1997) The cross-sectional determinants of emerging equity market returns, in Peter Carman (ed.) Quantitative Investing for the Global Markets - Strategies, Tactics and Advanced Analytical Techniques, Chapter 9, FitzroyFearborn Publishers, 221-272

Bekaert, G. and Harvey, C. (2003) Emerging market finance Journal of Empirical Finance, vol. $10,3-55$

Bekaert, G., Harvey, C. and Ng, A. (2005) Market integration and contagion. Journal of Business, vol. 78, no. 1, 39-69

Brav, A., Constantinides, G. and Géczy, C. (2002) Asset pricing with heterogeneous consumers and limited participation: empirical evidence. Journal of Political Economy, vol. 110, 793-824

Brennan, M. J., Wang, A. W. and Xia, Y. (2004) Estimation and test of a simple model of intertemporal capital asset pricing. Journal of Finance, vol. 59, no. 4, 1743-1775

Campbell, J. and Cochrane, J. H. (1999) By force of habit: a consumption-based explanation of aggregate stock market behaviour. Journal of Political Economy, vol. 107, no. 2, 205-251

Cappiello, L., Engle, R. and Sheppard, K. (2006) Asymmetric dynamics in the correlations of global equity and bond returns. Journal of Financial Econometrics, vol. 4, no. 4, 537-572

Chiarella, C., Dieci, R. and He, X. (2011) Do heterogeneous beliefs diversify market risk? European Journal of Finance, vol. 17, no. 3, 241-258

Diasakos, T. (2010) Comparative statics of general equilibrium asset prices. Carlo Alberto Notebooks, no. 72

Diebold, F. and Yilmaz, K. (2009) Measuring financial asset return and volatility spillovers, with application to global equity markets. Economic Journal, vol. 199, 158-171

Diebold, F. and Strasser, G. (2008) On the correlation structure of microstructure noise in theory and practice, CFS Working Paper, no. 2008,32

Easley, D. and O'Hara, M. (1992) Time and the process of security price adjustment. Journal of Finance, vol. 47, 576-605

Erb, C. and Harvery, C. (2006) The strategic and tactical value of commodity futures. Financial Analysts Journal, vol. 62, no. 2, 69-97

Fama, E., and French, K. (1993) Common risk factors in the returns on stocks and bonds. Journal of Financial Economics, vol.33, 3--56.

Gilbert, C. L. (2010) Commodity speculation and commodity investment. Commodity Market Review 2009-2010, FAO, 25-46 
Glosten, L. R. and Milgrom, P. R. (1985) Bid, ask, and transaction prices in a specialist market with heterogeneously informed traders. Journal of Financial Economics, vol. 14, 71-100

Hasbrouck, J. (2002) Stalking the efficient price in empirical microstructure specifications. Journal of Financial markets, vol. 5, 329-339

Heaton, J. and Lucas, D. (1996) Evaluating the effects of incomplete markets on risk-sharing and asset pricing. Journal of Political Economy, vol. 104, no. 3, 443-487

Hernandez, M. and Torero, M. (2010) Examining the dynamic relationship between spot and futures prices of agricultural commodities. Commodity Market Review 2009-2010, FAO, 47-86

Kalotychou, E., Staikouras, S. and Zhao, G. (2009) On the dynamics of asset correlations: What matters to portfolio managers. Cass Business School Working Paper

Karolyi, G. A. (2002) Did the Asian financial crisis scare foreign investors out of Japan? Pacific-Basin Finance Journal, vol. 10, 411-442

Karolyi, G. A. (2003) Does international financial contagion really exist? International Finance, vol. 6, no. 2, 179-199

Kelsey, D., Kozhan, R. and Pang, W. (2010) Asymmetric momentum effects under uncertainty. Review of Finance, vol. 15, 603-631

Kolanovic, M. (2011) Rise of cross-asset correlations: Asset class roadmap for equity investors. J.P.Morgan Global Equity Derivatives and Delta One Strategy Report

Kyle, A. S. (1985) Continuous auctions and insider trading. Econometrica, vol. 53, 1315-1336

Li, H. and Majerowska, E. (2008) Testing stock market linkages for Poland and Hungary: $A$ Multivariate GARCH approach, vol. 22, 247-266

Liu, Y. A. and Pan, M. (1997) Mean and volatility spillover effects in the U.S. and Pacific-Basin stock markets. Multinational Finance Journal, vol. 1, no. 1, 47-62

Mukherjee, K. N. and Misha, R. K. (2010) Stock market integration and volatility spillover: India and its Asian counterparts. Research in International Business and Finance, Vol. 24, 235-251

Pinto, B. and Utalov, S. (2010) Financial globalization and the Russian crisis of 1998. World Bank Policy Research Working Paper, no. 5312

Roll, R. (1984) A simple implicit measure of the effective bid-ask spread in an efficient market. Journal of Finance, vol. 39, 1127-1139

Tang, K. and Xiong, W. (2010) Index investment and financialization of commodities. NBER working paper, no. 16385

You, L and Diagler, R. T. (2010) Using four-moment tail risk to examine financial and commodity instrument diversification. Financial Review, vol. 45, 1101-1123 